\title{
Oxygen Effects in Anaerobic Digestion - A Review
}

\author{
Deshai Botheju* and Rune Bakke
}

Telemark University College, Norway

\begin{abstract}
This article reviews the experimental and theoretical studies conducted on the possible effects of oxygen in biogas generating anaerobic digesters. The interactions of oxygen with various biochemical processes associated with anaerobic digestion are discussed together with other relevant aspects. The conventional perception of oxygen being merely toxic in anaerobic digestion (AD) is refuted. Digesters can withstand significant levels of oxygenation without drastic negative impacts. Limited quantities of oxygen can even lead to improved AD reactor performance under certain operating conditions. Co-existence of anaerobic and aerobic cultures in a single bioreactor environment has been demonstrated. It is shown that the partial aeration assisted AD can serve as a beneficial treatment strategy for simultaneous waste treatment and energy generation, for a multitude of organic waste categories.
\end{abstract}

Keywords: Aeration, anaerobic digestion, hydrolysis, inhibition, methane, oxygen effects.

\section{INTRODUCTION}

\subsection{Anaerobic Digestion}

Anaerobic digestion (AD) is a biochemical process that converts a variety of organic matter using naturally occurring microorganisms under oxygen depleted conditions to produce a gaseous mixture mainly composed of methane and carbon dioxide, known as biogas. The biogas results from the microbial degradation of organic matter generally generated by photosynthesis using solar energy. The process can naturally occur in anaerobic environments like river sediments, deep soil or waste landfills. The AD process can also be engineered to take place in a dedicated facility known as an anaerobic digester; primarily a closed vessel kept with a culture of microorganisms, fed regularly with digestible (organic) matter.

It is suggested that the Sumerians used anaerobic cleansing of wastes 5000 years ago [1]. The Chinese may have used "matured" manure as a fertilizer 3000 years ago [2]. The first confirmed historical evidence of using biogas is found related to Assyria, where it was used for heating bath water during the $30^{\text {th }}$ century BP [3]. The first documented engineered anaerobic digester was put into operation in Mumbai, India in 1859 [4], using the process for waste treatment and utilizing biogas for lighting. The fundamental biochemical AD principles were started to be clearly understood only few decades ago. The process has been studied as a genuine scientific matter since the 1930's [3]. Even before that, some well known scientists including Volta, Faraday and Pasteur discovered some primary facts on biogas and its generation process. The definite chemical structure of methane was formulated due to the works of Dalton, Henry, Davy and Avogadro [1].

\footnotetext{
*Address correspondence to this author at the Telemark University College, Kjølnes Ring 56, P.O. Box 203, NO-3901, Porsgrunn, Norway: Tel: +4745075165; Fax: +4735575001; E-mail: Deshai.Botheju@hit.no
}

The anaerobic digestion has now become a well established technology used for handling multitudes of waste categories including those of domestic/municipal, agricultural and industrial origins [5-8]. Compared to alternative treatment methods, the merits of AD include low sludge production, high organic loading rates, energy value of methane and low energy consumption $[9,10]$. In the light of current global consciousness of environmental sustainability, $\mathrm{AD}$ is regarded as a promising process, both as a renewable energy generation scheme [11-13] and a waste stabilization method [14-17]. Anaerobic digesters further contribute to reduce greenhouse gas emissions [12, $13,18]$. Generation of nutrient rich digestates, which can be used as fertilizer [13, 17-19], is an added advantage. These merits of $\mathrm{AD}$ have led to a rapid growth of its application.

The primary problem faced by AD users is its inherent instability $[16,20]$ as a complex biochemical process $[21$, $22]$. AD is alarmingly sensitive to changes of operating and feed conditions. Accidental or unavoidable oxygen loading is one aspect of this problem. To cope with this inherent instability, it is essential to develop sufficient control techniques. Hence, a comprehensive mechanistic modeling approach towards the process is needed. Various attempts have been made to develop such models on anaerobic digestion and the most important milestone is the standard ADM 1 model [23]. The standard models, however, do not include all necessary aspects to accurately predict the digester behavior under different process disturbances. Lyberatos and Skiadas [24] made a review of early anaerobic digestion models and pointed out that modeling of digester behavior when exposed to an inhibiter (e.g. oxygen) is an area where further attention is necessary. Later modeling approaches published do not seem to make significant improvements in this regard. Botheju et al. [25] modified the standard ADM 1 model [23] to include the known oxygen effects as an attempt to investigate oxygen induced disturbances.

AD can also provide benefits from the different means of enhancing the process efficiency [26]. This may improve the 
economy of biogas generation plants enhancing the dissemination of such sustainable solutions. Partial aeration assisted anaerobic digestion has been recognized as a possible way to enhance AD performance [27-30].

\subsection{Different Phases of $A D$}

The overall AD process is a combination of a multitude of biochemical and physicochemical reactions. These can be basically categorized as disintegration, hydrolysis, fermentation (acidogenesis), acetogenesis (acetate generation) and methanogenesis (methane generation) [22, 23]. Disintegration involves physical and chemical breakdown of larger particulate matter. Hydrolysis is a step involving the enzyme-mediated chemical/biochemical transformation of long chain polymeric organic matter such as lipids, polysaccharides, protein, nucleic acids and fats into soluble and smaller organic molecules that can be consumed by microorganisms during the fermentation stage. These soluble components include fatty acids, monosaccharides, amino acids, simple aromatics and other short chain compounds [31, 32]. Hydrolysis is catalyzed by the extracellular enzymes excreted by the microorganisms responsible for fermentation/acidogenesis [32-34]. This group of organisms is considered to be composed of a large amount of facultative bacteria [33, 35-38] which can thrive with or without oxygen.

In the third stage of digestion, called acidogenesis/fermentation, the hydrolysis products are degraded to simpler compounds of volatile fatty acids (such as the acids of acetic, propionic, butyric, valeric, caproic and heptanoic), $\mathrm{CO}_{2}, \mathrm{H}_{2}$ and ethanol $[23,31]$. These compounds are the products of fermentative (anaerobic) respiration of acidogenic biomass. The fourth stage of digestion, acetogenesis, involves converting all volatile fatty acids (VFA) and some of the other short chain organic products (e.g. ethanol) into acetate, catalyzed by a separate syntrophic group of strictly anaerobic organisms, called acetogens. In the last stage, methanogenesis, acetate is converted into methane by a group of organisms called acetoclastic methanogens. Meanwhile, a part of the generated $\mathrm{CO}_{2}$ and $\mathrm{H}_{2}$ are utilized by another group of methanogens, called hydrogenotrophic methanogens, and again generate methane as the end product $[21,23,31]$. About $70 \%$ of methane is generated through the acetic acid pathway [39]. Methanogens belong to the strictly anaerobic microorganism group called archaea: About 19 genera and more than 50 species of methanogens have been identified so far [40]. The final gas mixture, biogas, can contain about $45-75 \% \mathrm{CH}_{4}$ and $20-50 \% \mathrm{CO}_{2}$ [41, 42, authors' own observations] plus minor amounts of $\mathrm{N}_{2}, \mathrm{H}_{2} \mathrm{~S}, \mathrm{H}_{2}, \mathrm{NH}_{3}, \mathrm{H}_{2} \mathrm{O}$ vapor and $\mathrm{O}_{2}$ [4143].

\subsection{Effects of Oxygen in $A D$}

It is quite natural that some amount of oxygen can reach anaerobic digesters unintentionally [44, 45] as the reactors are operated within an aerobic open environment, especially through interactions with the surroundings such as by feeding and mixing. Most anaerobic digesters are therefore subjected to minute and varying aerobic loading conditions. The possible effects of such aeration are neither extensively quantified nor handled in standard AD models. A few studies have, nevertheless, predicted and demonstrated benefits of adding some oxygen in AD [27-29, 44, 46-50].

It is commonly perceived that oxygen acts as an inhibitory and toxic agent [51-55] in AD due to the involvement of strictly anaerobic microorganism group of acetogens and methanogens [40]. Also, aerobic conversion of soluble organic matter into $\mathrm{CO}_{2}$ by aerobic respiration is likely. Thus, it was believed that reactor instabilities, slow start-ups, low methane yields and even total reactor failures might occur due to oxygen entering anaerobic digesters [44]. Due to this negative perception, inoculums used in anaerobic digesters are even de-aerated before commencing reactor operation; sometimes oxygen scavenging chemicals (e.g. sodium sulfide) are also being added [55-58]. Conversely, improved hydrolysis of particulate matter in $\mathrm{AD}$ is observed in the presence of oxygen $[49,59,60]$. All non-soluble and long chain organic matter should go through this initial hydrolysis stage before fermentation or methanogenesis, in which the particulate matter would undergo decomposition and solubilization by the activity of enzymes (such as protease, amylase, etc.) that are being extracellularly excreted by fermentative (acedogenic) bacteria [34]. Since hydrolysis is often the rate limiting reaction stage when the substrate is composed of particulate organic matter [32, 61, 62], enhanced hydrolysis can greatly benefit the overall process efficiency. It is commonly known that hydrolysis rates are significantly higher under aerobic and anoxic conditions compared to anaerobic conditions [63]. Botheju et al. [46] demonstrated the possibility of the existence of an optimum oxygenation level which would yield a maximum methane generation in AD.

The forthcoming sections discuss different aspects and possibilities of using limited oxygenation in AD based on the focus points of 1. Effects on physico-chemical and biochemical processes, 2. Microbial ecology, 3. Operation of partially aerated bioreactors, and 4. Modeling aspects.

\subsection{Terminology of Use}

The use of oxygen in an anaerobic process needs a specific phrase for the purpose of reference. The term "micro-aeration" has been used for this before, but over the years its usage has become confusing due to the fact that different authors use it with different meanings in their particular perspectives. In literature, the term "microaeration" has been found referring to several different conditions such as "the use of limited amount of air in an anaerobic process [59]", "use of small amount of oxygen dissolved in the medium [64], "use of oxygen with $<10 \% \mathrm{O}_{2}$ saturation [65]", "use of oxygen up to a certain fraction (10 - 15\%) of the total organic load [30]", "dissolved oxygen range where the optimum growth of microaerophilic organisms occur $(<1 \mu M-[66])$ ", “a low oxygen transfer rate scenario [67]" and several more, some with even mathematical definitions [68]. Several other authors, meanwhile, use this term without mentioning a definite range of oxygen. We may, however, encompass the majority of these definitions and usage by calling micro-aeration as a process where "some amount of oxygen is introduced to a basically anaerobic biochemical process".

In this article we, however, decided to avoid altogether the use of the term "micro-aeration". This is to be fair among 
the different authors, when we describe their findings. Instead, we will use the terms "limited aeration", "limited oxygenation" or "partial aeration" which we would similarly define as "a process where some amount of oxygen is introduced to a basically anaerobic biochemical process so that there would be both the anaerobic and aerobic biological activities happening in a single bio-reactor". This definition expects that the process should not become a complete aerobic process (having only aerobic activity) during the reactor operation (as it is to be a "basically anaerobic biochemical process"). However, the definition may allow the process to become, if it does, devoid of any aerobic activity at certain durations of operation. This definition is based on the aerobic and anaerobic activities of a bio-reactor rather than the load or level of oxygen introduction. Hence, it can be a general definition free from reactor configuration and operational effects. We may also use the phrase "oxygen limited conditions" to the situations where the oxygen supply rate is always maintained less than the oxygen utilization rate, so that there would not be any excess oxygen in the liquid phase and the DO reading should always be zero even under continuous oxygen/air supply.

\section{OXYGEN EFFECTS ON PHYSICO-CHEMICAL AND BIOCHEMICAL PROCESSES}

\subsection{Inhibitory and Toxic Effects of $O_{2}$ on Methanogens}

Methanogenic microorganisms (archaea) are categorized as the strictest anaerobes known, with little or no tolerance to oxygen $[57,58]$. This can be attributed to the fact that microbial group archaea has the oldest evolutionary history of all prokaryotes, dating back to the geological ages of the Earth when the atmospheric oxygen could not have been yet present [69]. It is claimed that strict anaerobes cannot synthesize the enzyme called superoxide dismutase which is used by aerobic organisms to neutralize toxic oxygen ions and radicals such as $\mathrm{O}_{2}{ }^{2-}, \mathrm{O}_{2}{ }^{-}$and $\mathrm{OH}^{-}[52,55,68,70,71]$. In addition, it is believed that the activities of some of the other important methanogenesis enzymes are also inhibited by oxygen [40]. For example, the pure cultures of the methanogenic species Methanococcus voltae and Methanococcus vannielii show almost a zero tolerance towards oxygen [72]. Whiteman et al. [40] reported that one species of Methanosarcina had a half time of survival of only 4 minuets in air equilibrated medium. On the other hand, some methanogenic species can have a certain extent of intrinsic tolerance to oxygen exposure [53]. Kiener and Leisinger [72] reported that the methanogenic species of Methanobacterium thermoautotrophicum, Methanobrevibacter arboriphilus and Methanosarcina barkeri did not show any reduction of colony forming units at the exposure to air for 30 hours; however, the longer exposure rapidly reduced the viability of the cells. It has now been confirmed that some methanogens do have the ability to produce superoxide dismutase enzymes $[44,52]$. Accordingly, different methanogenic organisms may differ in their intrinsic capability to tolerate different levels of oxygen presence [73]. Kato et al. [44] provides a list of different strict anaerobes with their nominal levels of superoxide dismutase which is the primary enzyme inducing the oxygen tolerance capability of those organisms [71]. It is plausible that some methanogens are evolved to handle different levels of oxygen upon the fact that their habitats are exposed to various oxygen levels throughout a long time period [55]. According to Gerritse et al. [74], when the cultures were adopted for oxygenation over a period of time, the same oxygen levels which were previously inhibitory, were not inducing any inhibition effect anymore.

Inhibitory characteristics of free oxygen towards strict anaerobic organisms present in anaerobic digesters have been investigated by a number of authors $[40,75,76]$. Scott et al. [75] experimenting on the oxygen sensitivity of methanogens, tested two different methanognic cultures, one from rumen and one from an anaerobic digester. Methane production stopped at below $30 \mathrm{nM}$ of oxygen concentration in both of the cultures. The exact low concentration where the oxygen inhibition starts could not be determined due to the limited sensitivity of oxygen probes [75]. This specific concentration, if determined, can be used to model the inhibition effect using an inhibition function (e.g. noncompetitive type) together with an inhibition coefficient $\left(\mathrm{K}_{\mathrm{i}, 02}\right)$.

Due to the generation of highly reactive oxidizing agents such as peroxides and superoxides in the liquid medium [70], it is suggested that not only functional inhibition but also rapid cell lysis [58] of obligatory anaerobic species can occur. As demonstrated by Martin and Savage [77] oxygen can damage the chromosomal DNA of strict anerobic microorganisms. According to Botheju and Bakke [47], the activity inhibition of methanogens and the complete destruction or cell lysis due to oxygen can be two different aspects of oxygen toxicity. They observed that rigorous initial aeration of an anaerobic inoculum resulted in a three times longer lag period before gas generation started, compared to an unaerated inoculum. This lag duration (3 days) was, however, similar for the different aeration levels denoted by the initial DO levels of 3,5 and $7 \mathrm{mg} / \mathrm{L}$. This is caused by the inhibition of methanogens due to rigorous initial aeration. The observed inhibition was found to be reversible since the gas generation started eventually. Reversibility of the oxygen inhibition of methanogens was observed also by Gerritse et al. [74]. Meanwhile, all the aerated inoculums eventually generated the same amount of methane, but the generation was increasingly slower at higher aeration levels most probably due to the permanent damage of a part of the strict anaerobes [47]. This is opposed to the comments made by Zitomer [53], who conducted an experimental series under limited oxygenation conditions, suggesting that methanogens might not have been killed by the introduction of oxygen but the activity was inhibited for a short period (30 min.). These opposing observations can be explained by the level or intensity of the aeration, as Botheju and Bakke [47] probably exposed their inoculums to much more oxygen than did Zitomer [53].

\subsection{Oxygen Shielding Effect and the Oxygen Tolerance of Strict Anaerobes}

It is suggested that anaerobic digestion systems can have considerable oxygen tolerance due to several deterrence mechanisms. Accordingly, strict anaerobes in an $\mathrm{AD}$ environment may survive and function under limited aeration with no or minor inhibitory effects. Primarily, rapid oxygen consumption ability of facultative fermentative organisms [56] can protect other organisms by scavenging on dissolved oxygen [55]. Microbial aggregates like flocs, 
granules and biofilms may shield organisms living deep inside diffusion barriers [54] which stop the full penetration by oxygen. Steep oxygen gradients are created through such microbial aggregates due to the diffusion limitation and also due to oxygen consumption by the facultative or aerobic organisms thriving closer to the surface of the aggregate/biofilm [30, 54, 55, 78, 79,].

While experimenting on a reactor arrangement called Membrane Micro-aerated Anaerobic Digester (MMAD), Rathnasiri et al. [78] and Botheju et al. [79] pointed out that oxygen supplied by aerated water circulation through a polydimethyl siloxane (PDMS) membrane tube did not reach the anaerobic bulk phase of the digester, when a biofilm layer was formed on the outer surface of the membrane. A modeling and simulation study carried out on this case [79], revealed that facultative organisms growing closer to the membrane surface consumed the supplied oxygen, leaving near zero dissolved oxygen values at the biofilm-digester bulk liquid interface. Methanogenic and acetogenic organisms were mainly accumulating at this biofilm-bulk liquid interface. Another interesting finding was that the membrane attached biofilm increased the oxygen mass transfer rate through the membrane compared to a clean membrane case [78]. This is due to the increased concentration driving force created by rapid oxygen consumption of facultative organisms in the biofilm.

Limited aeration caused no oxygen inhibition of the anaerobic microorganisms in a UASB (up-flow anaerobic sludge blanket) reactor, but only led to sulfide oxidation, according to a study by Zhou et al. [80]. Granular sludge in the UASB reactors could shield the methanogenic organisms from oxygen exposure, since they mainly grow inside the granules [54].

Studies have shown that at least some of the methanogenic organisms have an intrinsic capability of tolerating limited oxygen exposure for extended time periods $[51,55,72,81,82]$. Hence, together with this intrinsic tolerance, in a mixed consortium like the environment in an anaerobic digester, the methanogenic species should have a considerable ability to tolerate oxygen due to the presence of other (facultative) bacteria which help to reduce the oxygen stress on strict anaerobes. Survival of methanogens under low aeration conditions in a fully suspended medium in the absence of any microscopically observable flocs or aggregates has been described by Zitomer and Shrout [52] and also by Zitomer [53]. They confirmed that the majority of biomass was planktonic organisms. This observation cannot be explained by the existence of anaerobic microniches in biomass aggregates protected by diffusion barriers $[53,54]$, but by the oxygen shielding effect of facultative biomass. According to Kato et al. [55], a high correlation has been found between the oxygen tolerance and the oxygen uptake activity of the facultative bacteria in anaerobic granular sludge. But, a certain oxygen tolerance was still present even when the aerobic activity of the facultative organisms was absent [55]. This may be due to the intrinsic oxygen tolerance of strict anaerobes and/or the oxygen diffusion barriers through sludge granules. The above studies propose that the oxygen tolerance of many $\mathrm{AD}$ systems stems from a combination of several factors.
Conklin et al. [81] experimented on the effects of oxygen exposure on anaerobic digester sludge caused by recuperative thickening. They concluded that short term oxygen exposure did not significantly reduce the acetoclastic methanogenic activity. Prolonged oxygen exposure (over 7 days) did, however, decrease the methanogenic biomass activity with an oxygen lethality constant of 0.23 days $^{-1}$ for acetoclastic methanogens. Even with the lower methanogenic activity, long term oxygen exposure did not reduce the long term performance of the digester, but the ability of the digester to handle shock loads (digester reserve capacity) was significantly reduced by this long term oxygen exposure [81]. Peter and Conrad [83] concluded that, though methanogens cannot function in the presence of oxygen, they can survive longer time durations at oxygen exposure. Gerritse and Gottschal [84] studied the growth of the two methanogenic species Methanobacterium formicum and Methanosarcina barkeri, in mixed cultures by feeding a limited concentration of oxygen ( $450 \mu \mathrm{M} \mathrm{O}_{2}$ per hour). Their results showed a decrease in the methane formation rate compared to a complete anaerobic case, even though the growth of methanogenic organisms continued.

Shen and Guiot [54] observed that, in the long term, influent dissolved oxygen was inhibitory to acetogens and methanogens in a UASB type anaerobic/aerobic coupled reactor only when its concentration reached a certain high level, such as $8.1 \mathrm{mg} / \mathrm{L}$ in their experiment. This oxygen level certainly was a high value considering the high hydraulic loading rates of UASB reactors, and should have resulted in an oxygen non-limiting condition in the reactor liquid phase. Based on a model simulation, Botheju et al. $[79,85]$ concluded that typical dissolved oxygen concentrations found in influent streams of CSTR (continuous stirred tank reactor) type reactors could not cause a significant impact on digestion performance.

According to Hungate and Macy [73], oxygen was removed as rapidly as it entered an anaerobic habitat when enough substrate was present. Kato et al. [55] suggested that the presence of enough substrate was important for the oxygen tolerance of anaerobic cultures. Scott et al. [75] reported that an increased $\mathrm{O}_{2}$ uptake was noticed when an anaerobic inoculum was fed glucose. A certain lower level of oxygen tolerance was still noticed at no substrate feed conditions [55]. This can be due either to some intrinsic oxygen tolerance of organisms as mentioned before or to the presence of some substrates (including the decaying biomass) within the inoculum. More particulate matter in the inoculum may have been converted into soluble substrate due to oxygen enhanced hydrolysis [27, 49]. The possibility of some abiotic chemical oxygen uptake (e.g. sulfides) is also suggested as an explanation for such oxygen tolerance at no feed conditions $[55,86]$. Further, diffusion barriers due to aggregated biomass can always exclude the inhibitory oxygen effects as mentioned before, even under substrate limiting excess oxygen conditions. The effect of mixing on the oxygen tolerance of granular sludge was also studied by Kato et al. [55].The conclusion was that intense shaking reduced the oxygen tolerance in most cases. Mixing can increase the oxygen mass transport into the locations protected by diffusion barriers but dense aggregates can prevent oxygen penetration even with strong mixing. 
It has been reported that the population densities of methanogens in some paddy field soils do not change upon the seasonal changes of flooded anaerobic periods and dried aerobic periods [53,57]. This demonstrates the capability of methanogens to survive rather long durations of aerobic conditions. The availability of facultative and aerobic organisms together with organic substrates and also the diffusion barriers through soil particles may provide a significant protection to methanogens, as described before. Simon [20] stated that methanogens mixed with solid organic wastes demonstrated a high tolerance to aeration and did not show a significant reduction in methanogenic activity after the aeration period. Most probably, methanogens could have been well protected within the particulate solid matter avoiding exposure to much of the aeration.

\subsection{Use of Limited Aeration in Anaerobic Biochemical Conversions}

In addition to its potential use in $\mathrm{AD}$, limited aeration has been suggested to be advantageous in many other anaerobic biochemical conversion processes. Testing 2,3-butanediol production by the facultative anaerobe Enterobacter aerogenes as a model anaerobic process, Zeng and Deckwer [68] suggested that the use of limited aeration can help reduce the formation of toxic metabolites such as lactic acid and ethanol. They further showed the possibility of increased biomass and productivity under limited aeration, but excessive aeration could reduce the productivity by higher aerobic respiration and also inducing inhibition [68]. Another evidence for this product formation shift due to oxygen is found with the aero-tolerant lactic-acid bacteria Enterococcus $s p$. found in termite guts. This bacterium mainly produces lactate when fed glucose under anaerobic conditions, but when oxygen is added to the system mainly acetate is produced [87]. Testing the growth of the fermentative bacteria Lactococcus lactis under complete anaerobic, aerobic and limited aeration conditions, Nordkvist et al. [64] reported that the predominant lactate production culture showed a shift in by-product formation from formate, ethanol and acetate under complete anaerobic conditions to acetate, acetoin, pyruvate and $\mathrm{CO}_{2}$ under aerated and limited aeration conditions. They further reported that the maximum lactate yield and the minimum biomass yield were obtained under limited aeration conditions, compared to anaerobic and aerobic conditions. These studies indicate the possibility of using oxygen for controlling (by-) product formation in anaerobic biochemical processes.

As reported by Ghaly and El-Taweel [88], oxygen at very low concentrations is required by anaerobic yeast cultures to synthesize certain lipids needed to build cell walls. A similar finding was reported by Tango and Ghaly [89]. According to them, oxygen at low concentrations is essential for synthesizing oleic acid and ergosterol which are essential membrane components for certain anaerobic bacteria and, hence, stimulate the growth under anaerobic conditions. Franzen et al. [67] reported the need of trace amounts of oxygen for the yeast Saccharomyces cerevisiae in synthesizing sterols and unsaturated fatty acids. They further observed that limited aeration can be used to enhance the production of ethanol and minimize the formation of byproducts like glycerol. According to Franzen et al. [67] high aeration levels are, on the other hand, found to be disadvantageous due to the high aerobic respiration rates leading to increased biomass and $\mathrm{CO}_{2}$ generation. They highlighted the need of determining the optimum oxygen limited condition by using a unit-less parameter like respiratory quotient which is defined as the ratio between the $\mathrm{CO}_{2}$ evolution rate and the oxygen utilization rate. Experimenting on the effects of limited aeration on the growth of yeast Candida pseudotropicalis and production of ethanol during batch fermentation of cheese whey, Ghaly and El-Taweel [88] showed that increasing the rate of limited aeration decreased the lag period of growth and increased the specific growth rate, maximum cell number and also the substrate utilization rate. Meanwhile, the increased limited aeration increased the ethanol yield up to a certain aeration rate (up to $0.1 \mathrm{vvm}$. -volume of air per volume of culture per minute). Above that, the yield started to decrease as a result of the consumption of more substrate for biomass production, reducing the available substrate for ethanol production. It is known that some beer fermenting breweries use limited aeration effects to enhance their products (P. G. Rathnasiri - personal communication). Tango and Ghaly [89] studied the effects of limited aeration on the lactic acid production from cheese whey using anaerobic bacteria specie Lactobacillus helveticus. The findings are very similar to those by Ghaly and El-Taweel [88]. Limited aeration significantly improved the specific growth rate and enhanced the lactic acid yield while reducing the lag period of growth. The maximum cell number and also the substrate utilization rate increased with increasing aeration rate. Increasing aeration rate also increased the specific growth rate for any given initial lactose concentration, indicating that the limited aeration resulted in a culture that is more tolerant to substrate inhibition. After an optimum limited aeration rate of 0.1 vvm., the lactic acid yield started to decrease with increasing aeration. This is considered to be due to two factors: (i) utilization of more substrate (lactose) for cell synthesis (aerobic respiration) instead of product (lactic acid) formation (fermentation), and, (ii) oxygen toxicity to bacterial cells (apparent at the limited aeration rate of 0.15 vvm) which lead to an increased death rate of microbes. Using the facultative bacterium Klebsiella pneumoniae, Chen et al. [90] studied the different possible bioconversion pathways of glycerol into 1,3-propanediol (trymethylene glycol). Interestingly, a detailed stoichiometric and energetic analysis revealed that it was plausible to achieve a maximum theoretical yield of 0.85 mole 1,3-propanediol per mole glycerol under a limited aeration condition in comparison with the yield of $0.72 \mathrm{~mol} / \mathrm{mol}$ in fully anaerobic conditions. They further concluded that a limited aeration condition could be more ideal for the intended bioconversion than the strict anaerobic or fully aerobic environment. In the study of Chen et al. [90], a partially aerated condition was realized by aerating the culture at the beginning to its oxygen saturation with an aeration rate of $0.4 \mathrm{vvm}$. No aeration was allowed during the growth phase thereafter. Chen et al. [90] suggested that many enzymes found in facultative bacterial cells are similarly active in both the anaerobic and aerobic environments.

In order to conduct some biochemical conversions advantageously under limited aeration conditions, Liden et al. [45] suggested using varying (ramped) aeration rates to tally with the dynamically varying conditions in the reactor. 
This can be a suitable technique to exploit the maximum benefits of aeration, but it demands advanced control systems together with online measurements of reactor dynamics. Botheju et al. [46] pointed out that there exists an optimum oxygenation level giving rise to the maximum methane yield of an anaerobic digestion system but the optimum point may vary depending on several factors including the reactor biomass concentration and feed composition.

These findings show that limited aeration can be used as a way of improving anaerobic bio-conversions but optimization of the degree of aeration is necessary to achieve maximum benefits. The above findings also indicate that oxygen is essential for the stability of the cell membrane at least for certain anaerobic microbes. Further research would be helpful to confirm to what extent limited aeration can be used to optimize product formation of the bacterial and archaeal cultures typically found in anaerobic digesters.

\subsection{Aerobic Substrate Consumption}

With the availability of oxygen, facultative biomass can switch their metabolic function to aerobic respiration instead of fermentation, using readily available organic substrates such as monosaccharides, amino acids, long chain fatty acids (LCFA) and also volatile fatty acids (VFA) [91, 92]. This will generate $\mathrm{CO}_{2}$ as the metabolic end product instead of the VFAs under anaerobic fermentation. The facultative organisms can rapidly switch between aerobic respiration and anaerobic fermentation [68].

Methane generation reduced with increasing oxygen loads in a CSTR exposed to stepwise oxygen loading increases from zero to $2.5 \%, 5 \%$ and $10 \%$ (as \% of COD input) [28]. When the oxygenation levels were reversed from $10 \%$ to $0 \%$ in the same stepwise manner, the methane generation recovered rapidly at each step, showing no sign of significant biomass inhibition or damage due to oxygenation. Also the digester dynamics related to gas generation showed almost no hysteresis in increasing and decreasing oxygenation under the conditions tested. Increased $\mathrm{CO}_{2}$ generation and reduced $\mathrm{CH}_{4} / \mathrm{CO}_{2}$ ratio are observed at increasing oxygenation. It is concluded that the oxidation of soluble organic matter by aerobic respiration lead to these results. Johansen and Bakke [49] also observed increased $\mathrm{CO}_{2}$ production due to aeration while experimenting on the effects of limited aeration on hydrolysis in AD. Additional $\mathrm{CO}_{2}$ generation under limited aeration conditions is noted also by Hao et al. [59] while experimenting on the effects of partial aeration in hydrolysis stage of AD. Shen and Guiot [54] reported that the methanogens in a granular sludge survived oxygen exposure for 18 days when the substrate was supplied. It is conceivable that the supply of substrate leads to the consumption of oxygen by facultative organisms and reduces the oxygen stress on methanogens. They further reported reduced methane generation and increased $\mathrm{CO}_{2}$ generation due to aerobic substrate consumption. Joss et al. [93] mentioned that apart from aerobic respiration and $\mathrm{CO}_{2}$ generation, partial aeration in $\mathrm{AD}$ does not influence other biochemical interactions significantly.

It is also likely that, if the oxygen exposure level is sufficiently high, facultative organisms would, in the long run, out-compete strict anaerobes by rapid substrate uptake due to the high specific activities and growth rates. This can act as another form of inhibition of methanogens by substrate competition and would lead to reduced methane generation. Conklin et al. [81] reported that long term oxygen exposure led to reduced digester reserve capacity, probably caused by less methanogenic activity.

\subsection{Oxygen Effects on Hydrolysis}

Johansen and Bakke [49] showed that limited aeration can successfully be used to enhance hydrolysis during anaerobic digestion. These experiments were conducted in $500 \mathrm{ml}$ batch reactors by supplying air with a rate of 500 $\mathrm{ml} / \mathrm{d}$. The follow-up analysis revealed that about $50 \%$ increase in hydrolysis (based on COD) was obtained in the aerated reactors compared to the positive controls of strict anaerobic reactors maintained under the same operating conditions (mesophilic, $37^{\circ} \mathrm{C}$ ). The ratio of extra hydrolysis to oxygen utilization is calculated to be about $0.4 \mathrm{mg} \mathrm{C} / \mathrm{mg}$ $\mathrm{O}_{2}$. The increase in hydrolysis with limited aeration was only observed related to the carbohydrates and proteins, but no significant influence was found on lipids. Despite the enhanced hydrolysis, the aerated reactors produced $50 \%$ lower methane compared to the strict anaerobic control reactors. Increased hydrolytic effect may have been undermined by the faster aerobic respiration in the presence of an increased level of oxygen. Johansen and Bakke [49] pointed out the necessity of optimizing the oxygen supply in order to avoid excessive oxidation of hydrolyzed products to $\mathrm{CO}_{2}$. The biomass production was also found to be five times higher for the partially aerated reactors than that of the strictly anaerobic ones. While studying the effects of preaeration on the thermophilic anaerobic digestion of organic fraction of municipal solid wastes, Charles et al. [94] observed increased enzymatic activity related to the cellulase and protease (two hydrolytic enzymes) during the preaeration period. Drastic reductions of VFAs and soluble COD were also noted due to the aerobic substrate consumption. This is consistent with the findings of Botheju et al. [28] and Johansen and Bakke [49].

Wood feeding termites carry out an anaerobic mineralization process in their guts. Termites' extraordinary capability of degrading lignocellulosic substrate is believed to be derived from the rich microorganisms biota found in their guts and the diffusion of $\mathrm{O}_{2}$ through their gut wall [87]. This is a natural evidence for the relation between extreme hydrolysis capabilities and free oxygen. Zitomer and Shrout [52] described a batch experimental series where an aerated reactor showed a significantly higher residual soluble COD compared to an anaerobic and mildly aerated reactors. Release of soluble matter from microbial cells was suggested. Effects of two different aeration levels ( 0.4 and 0.08 vvm.) on the solubilisation of biological sludge by the aerobic thermophilic bacterium Bacillus stearothermophilus under the thermophilic condition of $65{ }^{\circ} \mathrm{C}$ were investigated by Hasegawa et al. [34] in a continuous flow reactor. Both aeration rates resulted in approximately similar VSS (volatile suspended solids) solubilisation of about $40 \%$ after an HRT (hydraulic retention time) of 1 day. The VFA accumulation, on the other hand, was significantly higher for the low aeration rate than high aeration. The high aeration condition could have further oxidized the generated VFA while the low aeration rate was sufficient enough for the solubilisation 
but was not enough for the subsequent VFA oxidation. Choosing the appropriate aeration level for solubilization without VFA oxidation is therefore obtainable. The enhanced solubilisation effects noticed by Hasegawa et al. [34] can also be contributed partly to thermal hydrolysis, in addition to the aeration effect.

Somewhat contrasting results of the aeration effects on hydrolysis are also presented: Hao et al. [59] found that high ("sufficient") aeration promoted the hydrolysis of biodegradable carbohydrates and proteins, while lower "insufficient" aeration impaired the hydrolysis potential of the system. Nguyen et al. [95] also concluded that no evidence was available in their study to suggest a positive effect of limited aeration on hydrolysis. They, however, observed increased AD biogas production when limited aeration was used as a pre-treatment. Goel et al. [96] reported that there was no significant difference in enzymatic activity under anaerobic and aerobic phases of a digestion system consisting of sequential batch reactors.

It can be hypothesized that more acidogenic biomass leads to more hydrolysis, since hydrolysis is carried out by the extracellular enzymes excreted by acidogens. In the presence of oxygen, facultative acidogens can have a higher yield, leading to a higher population and more enzymes. Gioannis et al. [35] reported that supplying of additional facultative biomass into the hydrolysis/acidogenesis stage of a two phase biogas reactor led to enhanced performance of the acidogenic reactor which then made a clear positive impact on the methanogenic reactor. It is also conceivable that the facultative organisms excrete a higher amount of enzymes in the presence of oxygen. Another plausible scenario is that oxygen itself or some of its radicals may act as agents carrying out a chemical hydrolysis, but this is unlikely to be important at limited aeration conditions, since no or very little oxygen is available in the liquid phase. Nevertheless, chemical hydrolysis effects of some strong oxidizing agents like $\mathrm{H}_{2} \mathrm{O}_{2}$ in bio-gasification processes have been observed [97].

\subsection{Sulfide Oxidation}

Several studies [29, 80, 86, 98] have demonstrated that limited aeration can be used to oxidize the sulfides generated in anaerobic digesters operating on $\mathrm{S}$ containing wastes. In anaerobic digestion, $\mathrm{S}$ compounds are reduced to $\mathrm{HS}^{-}$and $\mathrm{H}_{2} \mathrm{~S}$ by the biological activity of anaerobic sulfate reducing bacteria (SRB) [99]. Minimizing the sulfides content benefits the process by minimizing the toxic effect of aqueous sulfides on methanogenic and acetogenic organisms [29, 48, $80,98]$ and also eliminates the formation of toxic, odorous and corrosive $\mathrm{H}_{2} \mathrm{~S}$ gas $[11,86]$. SRB organisms compete with methanogens for organic substrates including acetate and hydrogen. Hence, $\mathrm{S}$ reducing activity leads to reduced methane yields $[48,80]$.

Zee et al. [86] using a fluidized bed anaerobic reactor $(1.7 \mathrm{~L})$ fed with low-sulfate vinasse, observed that the provision of an airflow of $0.7-0.9 \mathrm{~m}^{3} / \mathrm{m}^{3}$.d corresponding to $\mathrm{O}_{2} / \mathrm{S}$ molar ratios in the range of $8-10$, resulted in a complete removal of $\mathrm{H}_{2} \mathrm{~S}$ presence in the biogas. They suggested that sulfide oxidation can happen both by biological and non-biological mechanisms, confirmed by batch test studies involving active cultures, sterilized cultures and no biological cultures at all. The sulfide was observed to be primarily oxidized to elemental sulfur, thiosulfate and possibly polysulfate. Further oxidized forms such as sulfate did not occur under the low oxygenation conditions tested. Thiosulfate production was higher in the batch tests involving limited-aerobic culture. Sulfide removal rate was also faster in batch tests involving the partially aerated culture than the strict anaerobic culture. Zee et al. [86] further noticed that sulfide reappearance can also happen sometime after the sulfide oxidation, due to the activity of $\mathrm{S}$ reducing anaerobic organisms. However, this sulfide reappearance rate was always lower than the oxidation rate. The authors further concluded that oxygen uptake for sulfide oxidation could effectively over-compete the aerobic COD oxidation at these low aeration rates. Introduction of a low oxygen flow $\left(0.013-0.024 \mathrm{~L} \mathrm{O}_{2} / \mathrm{L}\right.$. d) into pilot scale CSTR reactors $(200 \mathrm{~L})$ fed with waste-water treatment plant (WWTP) sludge was capable of removing $\mathrm{H}_{2} \mathrm{~S}$ in biogas almost completely without affecting the biogas generation, methane content or COD removal efficiency, according to a study carried out by Polanco et al. [29]. They pointed out that the contact between $\mathrm{O}_{2}$ and the aqueous sulfides or the mass transfer also play an important role in the overall success of the approach. During a similar study on the partially aerated sulfide removal in AD [98] the level of air injection was precisely controlled by ORP (oxidation reduction potential) measurements so that oxygen inhibition of methanogens would not occur. $\mathrm{H}_{2} \mathrm{~S}$ content of the biogas was almost completely removed and more than $98 \%$ of the oxidized sulfide was recovered as elemental $\mathrm{S}$ with negligible sulfate production. These observations are similar to those made by Zee et al. [86]. Limited aeration (3 - 6 $\mathrm{ml} / \mathrm{L}$. min.) was used in a laboratory scale UASB reactor $(10.5 \mathrm{~L})$, fed evaporator condensate from a sulfite pulp mill, to overcome the serious sulfide inhibition, as reported by Zhou et al. [80]. Sulfide was oxidized mainly to elemental S which was non-toxic for microorganism. $\mathrm{H}_{2} \mathrm{~S}$ stripping caused by aeration was also thought to be playing a role in observed reduction of sulfides. Although the stoichiometric oxygen content needed to oxidize $1 \mathrm{mg}$ of $\mathrm{S}$ was $0.38 \mathrm{ml}$, a much higher aeration rate was needed due to the mass transfer limitation in the reaction system [80]. The possibility of mass transfer limitations in sulfide oxidation was pointed out by Polanco et al. [29] too. Tang et al. [100] also reported that limited aeration of an anaerobic digester led to considerable reduction of the concentration of $\mathrm{H}_{2} \mathrm{~S}$ in the biogas. The aerated digester had a $\mathrm{H}_{2} \mathrm{~S}$ content of $5 \mathrm{ppm}$. as compared to the strictly anaerobic reactor having 700 ppm. Conducting a batch experimental series under strictly anaerobic and oxygen limited conditions, Zitomer and Shrout [52] observed that strictly anaerobic culture broths were black in color all the time while the oxygen limited broths became brown over time. This was explained as less reduction of sulfate and/or iron to ferrous sulfide under oxygenated conditions.

\subsection{Effects on Intermediate Products ( $V F A)$}

According to Botheju et al. [28], introduction of partial aeration may lead to a reduced accumulation of VFA in anaerobic digesters. Introduction of aeration $\left(2.5 \% \mathrm{O}_{2}\right.$ load as $\%$ of feed COD) in a semi-continuously fed anaerobic digester (fed a synthetic substrate mixture containing starch, 
peptone and yeast extract) having 33 days HRT (hydraulic retention time) and a $0.33 \mathrm{~kg} \mathrm{COD} / \mathrm{m}^{3}$. d OLR, immediately resulted in a significant reduction $(80 \%)$ of total VFA content. Further increasing the $\mathrm{O}_{2}$ load to $5 \%$ and $10 \%$ led to even less VFA. The high initial VFA level was not recovered when the oxygen load was removed. This suggests that oxygenation can be helpful for stabilizing anaerobic digesters in their start-up period or during periods of reactor instability characterized by high accumulation of VFA. Following a three stage aerobic-anaerobic-aerobic sequential batch treatment of organic solid wastes, Simon [20] observed that the primary aeration stage considerably reduced the VFA accumulation and, thus, avoided digester souring of the anaerobic stage, resulting in a better methanogenic phase.

Rathnasiri et al. [78] observed a synchronized behavior of VFA with cyclic introduction of oxygen into a type of anaerobic reactor called Membrane Micro-aerated Anaerobic Digester (MMAD); higher oxygen utilization rates were detected corresponding to high VFA levels and vice versa. Zhou et al. [80] observed reduced VFA accumulation due to limited aeration in a UASB reactor. Effluent COD content was also reduced after aeration. Aerobic oxidation of reaction intermediates such as VFA and $\mathrm{H}_{2}$ was suggested by Zitomer and Shrout [52] too. Chu et al. [51] suggested the possibility of VFA and hydrogen oxidation due to the oxygen presence in their membrane granular sludge bed reactor operated under oxygen limited conditions. Gerritse et al. [74] also observed aerobic consumption of acetate and propionate when they increased the oxygen supply rate into a co-existing anaerobic and aerobic culture. According to an experiment conducted by Hasegawa et al. [34] to investigate the effects of pre-aerating biological sludge before biogasification, VFA oxidation was found to occur under higher aeration conditions while maintaining low aeration levels led to the accumulation of VFA.

It has been suggested that aeration might increase the proportional content of acetate in total VFA generation. Chu et al. [101] reported about $70-80 \%$ acetate content in total VFA by using an air flow rate of 0.126 volume of air per volume of sludge per hour, in a thermophilic aerobic digestion process. In comparison, a complete anaerobic fermentation process only generated acetate in the proportion of $\sim 40-50 \%$ [101]. That study further suggested VFA oxidation due to aerobic respiration. It is possible that the observed higher acetate content can be caused by the inhibition of methanogens under oxygenated conditions which would otherwise have consumed acetate. Aerobic VFA consumption on the other hand can similarly use up all the types of VFAs [28] and, therefore, do not offset the acetate proportion. Chu et al. [101], nevertheless, argued the possibility of an alternative oxygen assisted biochemical process which generated acetates, in addition to the common fermentation. However, strong experimental proof of the existence of such a biochemical pathway was not provided. VFA generation in aerobic sludge digestion processes is reported by several authors [101-104], mainly caused by low aeration and the creation of anaerobic zones where the fermentation can occur.

According to Tang et al. [100], limited aeration of 7.5\% $(\mathrm{v} / \mathrm{v})$ of the biogas generation rate did not lead to any difference in VFA concentration. Joss et al. [93] too observed that the amount and composition of VFA did not change when supplying oxygen into an anaerobic digester.

The contradicting results published can be explained as follows: It is likely that generation of additional VFA by the increased activity of acidogens and the consumption of VFA due to aerobic respiration and methanogenesis occurs concurrently in anaerobic digesters which are being partially aerated. Hence, the outcome of VFA concentration depends on the relative rates of generation and consumption of VFA. This will vary under different test conditions. Under stable and sound operating conditions, however, the consumption rate of VFA by aerobic respiration and methanogensis should supersede the rate of VFA generation.

\subsection{Effects on $p H$}

Aeration in $\mathrm{AD}$ can, as documented above, lead to reduced VFA accumulation and thereby prevent $\mathrm{pH}$ drops. A stripping effect on $\mathrm{CO}_{2}$ due to aeration can also prevent $\mathrm{pH}$ drops. According to Zitomer and Shrout [52], partially aerated complete-mixed digesters recovered from a $\mathrm{pH}$ drop more quickly than un-aerated reactors. Guiot et al. [105] observed $\mathrm{CO}_{2}$ stripping due to aeration, resulting in significantly higher $\mathrm{pH}$ in an aerated UASB reactor (aeration in recycle stream) compared to a strictly anaerobic reactor. Simon [20] reported that when pre-aeration was not used, $\mathrm{pH}$ dropped to a lower value of 5.2 in a reactor treating solid organic wastes. Botheju et al. [27], also observed a high initial $\mathrm{pH}$ drop in an un-aerated anaerobic reactor, compared to the aerated ones.

According to an experiment described by Zitomer and Shrout [52], when given a shock load of $4 \mathrm{~g} \mathrm{COD/L.d} \mathrm{to} \mathrm{a}$ series of bench scale batch reactors, the $\mathrm{pH}$ dropped to 5.0 from the initial 7.0. The completely anaerobic reactor did not recover to neutral $\mathrm{pH}$ in 52 days. The reactors supplied with limited oxygenations of 1 and $0.1 \mathrm{~g} / \mathrm{L} . \mathrm{d}$ returned to the initial pH after 34 and 28 days, respectively. Reduced VFA content and stripping of $\mathrm{CO}_{2}$ and $\mathrm{H}_{2}$ due to aeration were suggested as the reasons for this faster $\mathrm{pH}$ recovery. According to Zitomer [53], extra $\mathrm{CO}_{2}$ generation due to aeration may demand higher alkalinity for neutralizing $\mathrm{CO}_{2}$ acidity in anaerobic digesters, but this is not supported by experimental evidence.

Noticeable $\mathrm{pH}$ differences were not obtained in continuously fed anaerobic digesters operating under different oxygenation levels [28, 54]. This implies that limited aeration has no significant influence on $\mathrm{pH}$ under relatively stable operating conditions but it can prevent instabilities and augment recovery from $\mathrm{pH}$ instabilities.

\subsection{Methanotrophic Effect}

Presence of the specific microbial group called methanotrophes, which are capable of oxidizing $\mathrm{CH}_{4}$ into $\mathrm{CO}_{2}$ and water, might induce a negative effect on the methane potential of anaerobic digesters. These methanotrophes are mainly aerobic organisms and thus, in the presence of oxygen, they might play a significant role if sufficient amounts of organisms are available. It is estimated that some $17 \%$ of the natural methane generation in the world is degraded thanks to the action of methanotrophes in the open environment [1]. Some anaerobic methanotrophes have also been found [1]. 
The significance of methanotrophic processes in AD has not been widely reported. In several batch experimental series involving headspace aeration, Botheju and Bakke [47] detected a slight decrease in gas volume with time after the biogas generation had been halted due to substrate exhaustion. The methanotrophic methane consumption could have occurred throughout the experimental duration, but could only be detected when the gas generation stopped. Kato et al. [44] recognized methanotrophic bacterial groups in an anaerobic reactor exposed to prolonged aeration. Zitomer and Shrout [52] observed that exposing an anaerobic culture to $125 \%$ of oxygenation (as \% of COD input) resulted in very little methane in the off-gas but the culture was showing a high methanogenic activity. They concluded that aerobic oxidation of methane could have been the reason for this. Zitomer [53] also suggested methanotrophic activity caused by aerobic or microaerophilic bacteria. Zitomer [53] further cited the possibility of methane-utilizing methanotrophes to carry out co-metabolic biodegradation of highly chlorinated substances like tri/tetra chloro-ethylene, using methane as a co-substrate. If this claim can further be substantiated, it would make anaerobic digestion under partially aerated conditions even more attractive as a treatment strategy for bioremediation of a multitude of halogenic substances.

\subsection{Biogas Generation and Methane Yield}

It has been observed that limited aeration can enhance the methane yield in anaerobic digestion [27, 46, 47]. Botheju et al. [27, 46] studied the effects of different air and oxygen headspace volumes in anaerobic batch bioreactors fed with starch. They observed positive response due to oxygenation for a range of oxygenation loads $(0-16 \%)$ and also predicted the existence of an optimum oxygenation level corresponding to a maximum methane yield [46]. A few other studies also suggested that limited aeration can lead to enhanced methane generation [50, 74, 106]. Pirt and Lee [50] observed that traces of oxygen enhanced the anaerobic digestion of algal biomass in batch mode reactors. They reported that digesters fed with air produced biogas faster than strict anaerobic condition. Gerritse et al. [74] also reported that about a $20 \%$ increase in methane production was observed at low oxygen fluxes in a chemostat (dilution rate $0.06 \mathrm{~h}^{-1}$ ) provided with headspace oxygen. Further increasing the oxygen flux resulted in the washout of methanogens and accumulation of substrate. Botheju et al. [106-108], described the use of limited aeration in AD for the treatment and bio-gasification of waste monoethanolamine (MEA) generated in post combustion $\mathrm{CO}_{2}$ capture. Net methane generation by the degradation of waste MEA was positively influenced by the increasing oxygen loads (in the range of $0-0.39 \mathrm{ml} \mathrm{O} / \mathrm{ml}$ reactor content). The effect was more pronounced at a higher initial equivalent MEA concentration of $500 \mathrm{mg} / \mathrm{L}$ compared to a $125 \mathrm{mg} / \mathrm{L}$ concentration.

Tang et al. [100] reported that a microaeration level of $7.5 \%(\mathrm{v} / \mathrm{v})$ of the biogas generation rate did not make any difference in either biogas generation rate or methane concentration. However, their feed contained S compounds and they observed significant $\mathrm{H}_{2} \mathrm{~S}$ oxidation. The supplied oxygen could have been completely spent on $\mathrm{H}_{2} \mathrm{~S}$ oxidation. This observation is consistent with the study by Polanco et al. [29] where an aeration load of $0.013-0.024 \mathrm{~L} \mathrm{O}_{2} / \mathrm{L}$. d does not affect the biogas/methane generation but only the $\mathrm{H}_{2} \mathrm{~S}$ oxidation. It is clear that $\mathrm{H}_{2} \mathrm{~S}$ oxidation processes (both chemical and biochemical) are faster and can easily outcompete the other oxygen utilizing biochemical processes; even the aerobic respiration [86].

Decreased amounts of methane generation under increased aeration conditions have also been widely reported [28, 54, 91, 92]. O'Keefe and Chynoweth [92] observed decreased amounts of methane generation coupled with oxidative loss of soluble organic matter while experimenting on aeration effects in simulated landfill cells. According to Mshandete et al. [91], 9 hours of aerobic pre-treatment enhanced the methane potential from mesophilic anaerobic digestion of sisal pulp waste, but noted that increasing further aeration only resulted in a significant loss of methane potential due to aerobic substrate consumption. Shen and Guiot [54] reported lower methane yields in UASB-like reactors under various oxygenation rates, allegedly caused by aerobic substrate utilisation. According to their experiment, different dissolved oxygen concentrations of 0 , $0.6,2.1,4.3$ and $8.1 \mathrm{mg} / \mathrm{L}$ were maintained in the liquid phase of the UASB-like reactor fed with a synthetic substrate composed of $75 \%$ sucrose and $25 \%$ acetate. These conditions resulted in the $\mathrm{CH}_{4}$ yields (as \% of input COD) of $64.1,58.7,55.1,47.9$ and 41.6 respectively and the $\mathrm{CO}_{2}$ yields (L/g COD removed) of $0.23,0.25,0.33,0.32$ and 0.39 respectively. But, the specific anaerobic activity, related to the different substrates of glucose, propionate, hydrogen and acetate, of the granules were found to be not impaired by the aeration even after 3 months of operation. An exception to this was the $8.1 \mathrm{mg} / \mathrm{L}$ case in which the granular activity was reduced only after 3 months of operation. Interestingly, over a short period (1 month) even a higher activity was observed for acetate and glucose uptake, for the oxygenation level of $2.1 \mathrm{mg} / \mathrm{L}$ [54]. It is observed that reducing methane yields under increasing oxygen loads can approximately be described using near linear functions [25, 46]. The data reported by Shen and Guiot [54] support this idea.

Increased $\mathrm{CO}_{2}$ generation can happen as a result of aerobic substrate consumption in partially aerated anaerobic digestion. Even in the cases where a mild aeration condition improved the methane yield, a still higher increase of $\mathrm{CO}_{2}$ generation was observed, hence reducing the $\mathrm{CH}_{4} / \mathrm{CO}_{2}$ ratio upon increasing the aerobic load [27].

It is suggested that the response of oxygen in biogas generation can either be positive or negative based on several parameters, including the hydrolysis rate coefficient, biomass concentration, and in the case of continuous reactors, hydraulic retention time, organic loading rate, and the sludge age [46]. Increased hydrolysis rate coefficient (overall second order [25]) and increased biomass concentration will cause the optimum oxygenation point to shift towards zero. This means that under high "hydrolisability" conditions, there would not be any positive response by oxygen addition on the methane yield and the sole effect would become negative [28, 46]. In continuous operation mode, it is likely that low HRT conditions which would give rise to lower biomass and a shorter time for hydrolysis may favor positive oxygen effects while higher HRT with sludge recycling might lead to negative effects. 
Zeng and Deckwer [68] discussing the use of limited aeration in anaerobic production of 2,3 -butanediol (BD) pointed out that there is an optimal oxygen utilization rate which gives the maximum BD productivity for each hydraulic retention time (HRT). These authors also recognized the importance of biomass concentration in deciding the optimum aeration level.

\section{OXYGEN EFFECTS ON MICROBIAL ECOLOGY}

Tang et al. [100] concluded that limited aeration did not produce a significant phylogenetic diversity in their thermophilic $\left(53{ }^{\circ} \mathrm{C}\right)$ anaerobic digester fed with synthetically made municipal solid waste, aerated continuously by air with a rate of $7.5 \%(\mathrm{v} / \mathrm{v})$ of the biogas generation rate. This simply means that limited aeration may not lead to dramatic differences in the microbial community structure. Tang et al. [100] arrived at this conclusion by establishing and comparing the genetic diversity trees for the cultures grown in partially aerated and fully anaerobic reactors. Further they noticed that several other parameters including VSS digestion efficiency, TOC (total organic carbon) concentration, VFA concentration, biogas generation rate and also the concentration of methane were almost the same for two different digesters (partially aerated and fully anaerobic). However, the concentration of $\mathrm{H}_{2} \mathrm{~S}$ in the biogas was considerably lower for the partially aerated reactor. Interestingly, the authors also noticed that although $\mathrm{H}_{2} \mathrm{~S}$ concentration was low in the aerated reactor, according to the gene analysis there was no evidence for any reduced SRB activity in the partially aerated reactor. This may suggest that $\mathrm{H}_{2} \mathrm{~S}$ reduction in this partially aerated reactor was caused mainly by a chemical effect of oxidation of $\mathrm{H}_{2} \mathrm{~S}$ rather than a result of inhibition of SRB. The results of the study by Duangmanee et al. [98], which has been discussed earlier, can also be explained by this argument. Though limited aeration did not change the phylogenetic diversity, it did reduce the size of the population of a group of methanogens, Methanosarcina, by about $50 \%$, and conversely the population size of another group of methanogens, Methanoculleus, was dramatically increased, by almost $100 \%$ [100]. This is evidently due to the difference in oxygen tolerability of different methanogenic organisms as discussed before; in the presence of oxygen, certain microbial species with higher oxygen tolerability can out-compete others having less oxygen tolerance.

Zee et al. [86] suggested that there is a possibility of growth of (poly) sulfide oxidizing bacteria in a partially aerated anaerobic digester fed with low sulfate vinasse. The sulfide removal rate was higher for the batch tests conducted with partially aerated culture compared to a complete anaerobic culture. Conversely, after sulfide reduction, sulfide reappearance was also faster in the partially aerated culture indicating the possibility of an increased population of polysulfide, sulfur and thiosulfate reducing bacteria [86]. Studying the sulfide removal by limited aeration in a UASB reactor fed evaporator condensate from a sulfite pulp mill, Zhou et al. [80] observed that aeration caused rod shaped methanogens to disappear from the sludge granules and afterwards the filamentous and cocci shaped methanogens predominated. Initially the granules consisted of mainly filamentous methanogens and some amounts of rod shaped methanogens. This observation suggests that certain shifts in methanogenic species population can occur due to aeration.
According to the study by Chen et al. [109], it was observed that anaerobic attached film expanded bed reactors (AAFEB) with pre-aerated biofilm carriers had an increased ability to withstand shock load conditions compared to the non pre-aerated ones and concluded that pre-aeration helped the growth of a more diversified and a viable culture. Preaeration further helped a faster biofilm formation, significantly shortening the start-up time. Faster growth of microbes under aerobic conditions can also generate higher amounts of exopolymers, which are the key binding agents for biofilm formation [110]. Additionally, aeration may have supported the growth of filamentous organisms which can capture free flowing organisms and accelerate biofilm growth [109]. It is conceivable that pre-aeration can be used as a technique to shorten the start-up time of regular UASB reactors by faster granule formation. Further studies are, however, needed to confirm this possibility.

Tango and Ghaly [89] and Ghaly and El-Taweel [88] demonstrated that the limited aeration greatly affects the cell growth. At a given substrate concentration, increasing aeration resulted in a higher specific growth rate, hence the culture became more tolerant against substrate inhibition. Furthermore, aeration shortens the lag period of the microorganism growth pattern. This indicates that partial aeration is a successful strategy for recalcitrant waste digestion. However, Conklin et al. [81] reported that microaeration lead to reduced digester reserve capacity (capacity to tolerate shock loads in AD), probably caused by the lesser activity of methanogens in the presence of oxygen. In contrast, Zitomer and Shrout [52] mentioned that the specific methanogenic activity was higher for some cultures which received oxygen than the cultures maintained under strict anaerobic conditions. Even though Shen and Guiot [54] have also reported such an observation over a short period (1 month) of operation of their UASB-like reactor, these observations must further be elucidated with more confirming experiments and theoretical explanations.

Under very low dissolved oxygen concentrations $(<1 \mu \mathrm{M})$, growth of a specific group of bacteria called "microaerophiles" can occur [66]. These non-fermentative bacteria do not belong to any of the conventional microorganisms groups of anaerobic, aerobic or facultative. This fourth kind of organism can only thrive within a niche of very low dissolved oxygen range which is left blank due to the low activity of anaerobic, aerobic and also facultative organisms at this specific low oxygen range [66]. Whether microaerophilic organisms can be present in significant numbers in anaerobic digesters maintained under limited aeration conditions or whether they would play any significant role in such cases is still unclear and should be addressed in future studies. But it can be predicted that their activity will mainly be restricted to aerobic respiration as this group of organisms are known to be non-fermentative.

\section{OPERATION OF PARTIALLY AERATED ANAEROBIC BIOREACTORS}

\subsection{Co-Existing Anaerobic - Aerobic Cultures}

Co-existence of anaerobic and aerobic respiring cultures is possible due to the several deterrence mechanisms explained before, namely, oxygen shielding effect by facultative organisms, diffusion barriers, and limited intrinsic 
oxygen tolerance of some strict anaerobes. Simultaneous maintenance of both aerobic and anaerobic activities in (semi) continuous bioreactors has been demonstrated in a study conducted by Botheju et al. [27, 28]. Simultaneous oxygen consumption and methane generation was observed. In this study, methanogenic activity was sustained with no notable prolonged inhibition under the presence of oxygen (up to $10.1 \%$ of input COD) in a suspended biomass semicontinuously fed and partially aerated reactor system. The methane yield showed a negative impact by the aeration, but the lower COD content under partially aerated operation resulted in a superior effluent quality.

By carrying out a biofilm simulation on a membrane microaerated anaerobic digester (MMAD), Botheju et al. [79] indicated the possibility of having a fixed film of biomass which could perform aerobic metabolism even in an anaerobic bulk phase. A high amount of facultative organisms was seen growing at the bottom of the biofilm (on the membrane surface, where free oxygen is available), while anaerobic organisms dominate near to the membrane-bulk liquid interface. Zitomer and Shrout [52], also demonstrated the feasibility of maintaining aerobic respiration and methanogenesis using a common mixed culture in a single bioreactor. Zitomer [53] emphasized the necessity of investigating the co-existing anaerobic/aerobic activities in continuous feed reactors.

Gerritse et al. [74] observed that co-existing bacterial cultures of obligate aerobe Pseudomonas testosterone and anerobe Veillonella alcalescens were sharing a common habitat and competing for a common substrate over a wide range of oxygen supply rates, confirming the possibility of the simultaneous maintenance of aerobic and anaerobic activities in a single bioreactor. Furthermore, Gerritse et al. [74] showed that the anaerobe $V$. alcalescens could not grow alone in an aerobic media and its growth was completely inhibited at a very low oxygen level which was even below the detection limits of the measuring instruments used. This highlights the fact that anaerobic organisms mostly depend on the aerobic activity of their counterparts to shield themselves from high oxygen tensions. Also, Gerritse et al. [74] were able to control the competition between these two organisms by controlling the oxygen supply rate. At increasing oxygen supply rates, $\mathrm{CO}_{2}$ production increased due to the higher activity of $P$. testosterone. The acetate and propionate concentration decreased mainly due to the consumption by $P$. testosterone. Accordingly, it is deemed possible to manipulate the substrate competition between facultative organisms and strictly anaerobic methanogens by adjusting the oxygen input to the reactor, as also observed by Shen and Guiot [54]. This strategy enables bioreactors to perform simultaneous oxygen consumption, acid production and methane generation and also may improve the methane yield of the reactors. Kato et al. [44] discussed several such cases and suggested that enhanced methane generation could be realized due to the enhanced production of acids by facultative bacteria, hence stimulating the methanogenesis with more substrates (especially in the case of particulate feeds).

\subsection{Degradation of Recalcitrant and Toxic Organics Using Aeration Assisted $A D$}

Effluent streams generated by anaerobic digesters can contain an undigested COD fraction which is composed of different refractory organic matter resisting anaerobic degradation [54, 111]. Various types of pre-treatment for AD has been suggested for enhanced waste treatment and stabilisation, such as thermal, ultrasonic, chemical (ozone, $\mathrm{H}_{2} \mathrm{O}_{2}$, etc.) and enzymatic pre-treatment [34, 97, 112-115]. The feasibility of many such treatment options are, however, not well proven either economically or technically. Partially aerated anaerobic digestion can be a viable and simple alternative for enhanced waste treatment.

Co-existing anaerobic - aerobic reactor systems may also open new opportunities for biodegradation and bioremediation of recalcitrant compounds and toxic xenobiotics [54]. There are a number of case studies showing that a combined activity of aerobic and anaerobic organisms is needed for degrading or mineralizing some chemical substances [44, 68]. Simultaneous aerobic/anaerobic reactor systems can be an attractive alternative because of significantly lower capital and operating cost.

According to a study on the use of partial aeration in AD treating monoethanolamine (MEA) wastes generated in post combustion $\mathrm{CO}_{2}$ capture, Botheju et al. [106, 107] indicated the possibility of enhanced methane generation from MEA wastes using partial aeration assisted AD. This observation can be explained by the MEA degradation mechanisms suggested by Ohtaguchi et al. [116]. The presence of oxygen in the digester may have enabled it to degrade MEA to $\mathrm{CH}_{3} \mathrm{COOH}$ with faster kinetics and hence the anaerobic culture did not have to cope with a high MEA concentration and resultant substrate inhibition. An associated BOD (biological oxygen demand) test also revealed that aerobic degradation of MEA is possible with faster kinetics and also with higher amine concentrations compared to anaerobic degradation [106]. The hypothesis of Tango and Ghaly [89] and Ghaly and El-Taweel [88] that enhanced cell yields by aeration lead to stronger cultures which are more tolerable for substrate inhibition, may also be relevant in explaining these observations.

Some compounds or micro-pollutants inducing a toxic effect on one group of organisms can be used as a substrate for other organisms. For example, in forest industry wastewater, the BOD caused by resin acids are toxic for anaerobic cultures but can be consumed by aerobic or facultative organisms [44]. Aeration assisted AD could therefore be suited for energy recovery from pulp/paper industry wastewater containing such resin acids.

The ability of the facultative microorganisms to break down azo-bonds in azo dyes used in textile industry, under low aeration conditions has been documented [117]. Azo compounds resist the oxidative degradation by aerobic bacteria [118], due to the chemical structure of the $\mathrm{N}=\mathrm{N}$ azolinkage. These compounds can however be reduced under either strict anaerobic or partially aerated conditions by the action of strict anaerobic or facultative anaerobic organisms [117]. This reduction process generates aromatic amines [119] which can be completely degraded by aerobic biodegradation. Hence, an anaerobic treatment design with limited aeration can achieve complete degradation of azo dyes containing textile wastewater. Use of an additional readily degradable co-substrate can sometimes be necessary [52, 106, 117]. Sandhya et al. [117] used starch as a cosubstrate in their investigation. Botheju et al. [106] used this 
co-metabolic approach with apple juice as the co-substrate for the successful anaerobic methanogenic degradation of waste MEA generated in post combustion $\mathrm{CO}_{2}$ capture. This acidic co-substrate addition further helped to decrease the above-neutral $\mathrm{pH}$ conditions typical for amine wastes. Furthermore, a more suitable $\mathrm{C} / \mathrm{N}$ ratio was realized by adding this $\mathrm{C}$ rich co-substrate. The usefulness of aerobicanaerobic treatment schemes for recalcitrant, persistent and eco-toxic organic waste, has also been pointed out by Song and Logan [56]. A few case studies on the degradation of various chlorinated compounds and polycyclic aromatic compounds by Zitomer and Shrout [52] indicated that oxygen can promote different degradation reactions of various compounds by different mechanisms.

\section{3. $\mathrm{O}_{2}$ Effects in High Rate Aggregated Biomass Reactors}

Quite different to the completely mixed suspended biomass (CSTR type) reactors, higher unintentional aeration can occur in high rate reactor configurations like up-flow anaerobic sludge blanket (UASB) and expanded granular sludge bed (EGSB), mainly due to the very high hydraulic loading conditions and extensive recycle streams [44]. Inflows of such reactors can carry a significant amount of oxygen load as dissolved oxygen and such reactors are often used for relatively low organic feed concentrations, leading to significant inflow $\mathrm{O}_{2} / \mathrm{COD}$ ratios. Kato et al. [55] claimed that oxygen toxicity would never occur due to dissolved oxygen entering anaerobic digesters with feed influent streams. Granular/aggregated sludge provides diffusion protection from oxygen for strict anaerobes in such processes, preventing detrimental effects. Using microelectrodes and confocal scanning laser microscopy, de Beer et al. [120] showed that oxygen did only penetrate into the first 30 $\mu \mathrm{m}$ of a $90 \mu \mathrm{m}$ thick biofilm cell cluster. However, oxygen was found in biofilm pores and channel-like structures. Methanogenic biofilms are known to be more porous and channeled than aerobic films, probably because methanogenic films generate large amounts of gas [120, 121]. Kato et al. [44] suggested that oxygen generally could not penetrate more than the first few hundred micrometers in thick biofilms. According to Chu et al. [51], methanogens in granular sludge are protected due to diffusion limitation of oxygen. Methanogenesis mainly occurs deep inside the granules while facultative and aerobic biomass dominate near the surface of the granules [54]. Kato et al. [55] observed that a granular sludge was capable of maintaining high methanogenic activity together with high oxygen tolerance. A considerable methanogenic activity was still present even at a dissolved oxygen concentration of 12.4 $\mathrm{mg} / \mathrm{L}$ (using pure oxygen). Wu et al. [122] demonstrated the possibility of establishing anaerobic granular sludge in a UASB reactor seeded with flocular sludge from an aeration tank treating sewage.

Chu et al. [51], experimenting on a membrane bioreactor with granular sludge bed seeded with anaerobic granules, observed simultaneous removal of organic substrates and nitrogen from synthetic wastewater containing sugar, potato starch and peptone, under an oxygen limited operation. In this case, in addition to methane generation, nitrification may have occurred on and near the surface of the granules, with denitrification in deeper layers. Aeration was carried out by
15 min. on and 15 min. off cycles with a 3 - $4 \mathrm{~g} \mathrm{O}_{2} / \mathrm{L} . \mathrm{d}$ load. It was observed that the granules adapted to the oxygen limited operation and became slightly lower in density (1030 $\mathrm{kg} / \mathrm{m}^{3}$ for anaerobic and $1010 \mathrm{~kg} / \mathrm{m}^{3}$ for partially aerated operation). The specific methanogenic activity decreased by $\sim 25 \%$ (1.48 and $1.12 \mathrm{~g} \mathrm{CH}_{4}$-COD/g VSS. $\mathrm{d}$ for anaerobic and partially aerated, respectively). The experimental reactor used by Chu et al. [51] had two distinguishable reaction zones: A limited aeration zone within the granular sludge bed and a more aerobic zone above the granular sludge bed. Shen and Guiot [54], also observed that the sludge volume index (SVI) of a granular sludge increased due to exposure to increasing levels of oxygenation, resulting in reduced sludge settling and some sludge washout. The level of dissolved oxygen concentration was found to be correlated to the sludge washout rate [54]. This could have been caused by growth of a fluffy aerobic or facultative biomass on the granule surface.

Kato et al. [55] observed that the granule diameter did not correlate with the oxygen tolerance of anaerobic granular sludge. Also they did not detect any effect on the oxygen tolerance of granules even after they crushed the granules to reduce their size. This implies that granules generally have a much greater thickness $(0.5-5 \mathrm{~mm}$ [123]) compared to what is needed to protect them from complete oxygen penetration. De Beer et al. [120] reported oxygen penetrated to only about $30 \mu \mathrm{m}$ depth in a biofilm.

\subsection{Limited Aeration as a Pre-Treatment in $A D$}

Limited aeration can be used as a pre-treatment prior to anaerobic digestion to enhance the digestibility of different types of wastes. Limited aeration has been tested as a pretreatment prior to anaerobic digestion of municipal organic solid waste by Nguyen et al. [95] and Juanga et al. [124]. According to these two studies, waste bed reactors which were effectively partially aerated by sending air through the bed (flow rate $0.4 \mathrm{~L} / \mathrm{kg}$. hr.) in a " $2 \mathrm{hr}$. run $4 \mathrm{hr}$. stop" mode for a 5 day period before inoculation and anaerobic digestion phase started, showed a considerably improved methanogenic stage performance compared to the reactors which were not aerated. Not only did the pre-aerated reactor produce a higher biogas volume but it also reached the active methane phase (50\% methane in gas) quicker than the rest of the reactors. This is a clear indication of a positive effect that partially aerated pre-treatment can pose on anaerobic digester performance. The rapid increase in gas generation observed just after the lag phase may suggest that partial aeration could have also resulted in better acidification providing enough substrate for methanogens. Akashi et al. [125] reported a significant increase in biogas generation as a result of partially aerated pre-treatment. They observed an impressive 1.5 times higher biogas generation from biological sludge when pretreated by partial aeration than the anaerobic operation alone. Experimenting on the effect of thermophilic $\left(65^{\circ} \mathrm{C}\right)$ aerobic pre-treatment on biogasification, Hasegawa et al. [34] showed that a low aeration rate of $0.08 \mathrm{vvm}$. led to an increased biogas generation by a factor of 1.5, compared to an untreated sludge. The higher aeration rate of $0.4 \mathrm{vvm}$. had only a slight positive effect on biogas generation. Pre-aeration helped increase methane generation at the start-up of a biogas reactor treating organic 
solid waste, by avoiding the digester souring, according to Simon [20].

\subsection{Post Anaerobic Aeration}

Aerobic respiration activity can increase the sludge production [126, 127] of a digestion process. However, lower level of aeration may result in less production. Use of anaerobic digester sludge (digestate) as a valuable fertilizer or a soil amendment is promoted [13, 17-19, 128] as a sustainable nutrient recycling process. It has been observed that $\mathrm{AD}$ increases the plant available nutrient content of the organic wastes [13]. In that sense, partial aeration can result in a more stable and a safer product. This is due to the reduced contents of organics, malodorous products $\left(\mathrm{H}_{2} \mathrm{~S}\right.$, VFA) and pathogens [28, 29, 129]. Botheju et al. [19, 128] reported the possibility of using post-anaerobic nitrification to greatly reduce the content of toxic heavy metals content in an anaerobic digestate from a plant treating municipal organic wastes. This allows the digestate to be qualified as a high ranking organic fertiliser in addition to the achievement of $\mathrm{N}$ stability. Other authors have suggested post-anaerobic aeration as a polishing stage for anaerobic digestates in order to improve $\mathrm{C}$ and $\mathrm{N}$ removal [44, 130].

Nitrification by post aeration of anaerobic effluents as described by Botheju et al. $[19,128]$ can be a useful way to convert digestates rich in amonical nitrogen into a valuable liquid $\mathrm{N}$ fertilizer product. The common practice today is to dewater the anaerobic effluents and to use only the solid fraction as a soil amendment or a fertilizer, while the liquid fraction is discarded as wastewater. This release of $\mathrm{NH}_{4}-\mathrm{N}$ can account for up to $50 \%$ of the total ammonium load of a municipal wastewater treatment plant [131]. Post-anaerobic aeration of digestates is useful also as a secondary treatment to achieve better effluent quality and sometimes to comply with local regulations on land application of digestates [130]. Anaerobic digestion of typical municipal wastes often lead to effluent streams with $1000-3000 \mathrm{mg} / \mathrm{L} \mathrm{NH} \mathrm{NH}_{4} \mathrm{~N}$ and COD loads higher than $1000 \mathrm{mg} / \mathrm{L}[19,131,132]$. Nitrogen present in protein containing food residues ends up as $\mathrm{NH}_{4}-\mathrm{N}$ in anaerobic effluents that cannot be further converted into nitrate $\left(\mathrm{NO}_{3}-\mathrm{N}\right)$ without an aerobic treatment stage [133]. When the anaerobic effluent is used as $\mathrm{N}$ fertilizer, which is increasingly encouraged as a nutrient recycle strategy, nitrate $\left(\mathrm{NO}_{3}-\mathrm{N}\right)$ is the preferred form of $\mathrm{N}$, as ammonical nitrogen $\left(\mathrm{NH}_{4}-\mathrm{N}\right)$ is more unstable and also can lead to root zone acidification in plants [134]. $\mathrm{NO}_{3}-\mathrm{N}$, on the other hand, is a highly mobile and easily available $\mathrm{N}$ source for crops [135]. Accordingly, the post anaerobic nitrification scheme proposed by Botheju et al. $[19,128]$ can be a reasonable way of recycling nutrients in $\mathrm{AD}$ treatment. It is shown that over $70 \%$ ammonical $\mathrm{N}$ conversions can be achieved and $\mathrm{pH}$ can be used as a simple and good enough monitoring parameter for the successful operation of the process [19, 131]. Interestingly, it has been reported that ammonia oxidizing (nitrifying) bacteria can survive unharmed in anaerobic digesters [130]. This suggests that co-digestion of waste activated sludge and municipal organic wastes can be useful in achieving high nitrifying biomass contents in postanaerobic nitrification. Nitrifiers are slow growing microorganisms [133] and highly susceptible to washout and overload [19]. Furthermore, it may be worthwhile to study the possibility of simultaneous methanogenesis and nitrification under oxygen limiting conditions. Some N loss through denitrification will, however, occur under reduced conditions. Even though, Lie and Welander [136] stated that denitrification can be inhibited at very low DO concentrations $(<0.1 \mathrm{mg} / \mathrm{L})$, Bakke (R. Bakke - unpublished data) observed that denitrification occurred in partially aerated methanogenic reactors.

\subsection{Self Heating Capacity}

Aerobic respiration activity associated with an anaerobic process can lead to a significant biochemical heat generation [94]. This heat generation can be used to elevate the reactor temperature into the thermophilic range $\left(\sim 55{ }^{\circ} \mathrm{C}\right)$. Thermophilic anaerobic digestion generally delivers superior process efficiencies compared to mesophilic $\left(\sim 35{ }^{\circ} \mathrm{C}\right)$ digestion $[114,137]$, mainly due to the faster kinetics at elevated temperatures $[22,138]$. Another aspect of great importance is that thermophilic anaerobic digestion can extensively reduce the pathogens content in the digestate $[61,129,137]$. Smith et al. [129] concluded that a mere 20 $60 \mathrm{~min}$. holding time was sufficient to achieve a complete pathogen destruction in thermophilic (at $55{ }^{\circ} \mathrm{C}$ ) anaerobic digestion, while mesophilic digestion could not demonstrate adequate pathogen reduction. Anaerobic digester operators in some countries are legally directed to heat up their digestates in order to ensure pathogen reduction [139]. For that reason, some plants are designed to operate in sequential anaerobicaerobic mode completing the pathogen destruction in the aerobic stage [139]. Aerobic-anaerobic sequential treatment can also be applied. In Norway, an upstream micro-aerobic hygenisation stage (temp $>70{ }^{\circ} \mathrm{C}$ and retention time $>2 \mathrm{hrs}$.) is used in digesters operating on municipal wastewater sludge [28]. This configuration was also applied to enhance the digester efficiency, probably caused by enhanced hydrolysis due to partially aerated pre-treatment and elevated temperature. By this means, a part of the energy lost owing to reduced methane yield due to aerobic respiration can be reclaimed as microbial heat. Further, a common observation is that thermophilic digesters are relatively unstable compared to the mesophilic operation [61, 138, 140]. However, partial aeration can successfully be used to enhance the stability of such digestion systems through reduced accumulation of VFAs [28].

Joss et al. [93] stated that partial aeration in anaerobic digestion can supply a heat yield of $14.5 \mathrm{MJ} / \mathrm{kg} \mathrm{O}_{2}$.

\subsection{Explosion Safety}

Methane and oxygen can form dangerous and explosive gas mixtures [31, 141] within the explosive range of $5-15 \%$ of $\mathrm{CH}_{4}$ [142]. There is a likelihood of creating such gas mixtures in a partially aerated anaerobic reactor. Hence, any experimental or large scale bio-gasification process involving oxygen/aeration must consider this fact and consider necessary safety designs. If such a possibility is identified, actions must be taken to adjust the aeration rate so that the explosion range will be avoided. It is, nevertheless, observed that the presence of various inert gases like $\mathrm{CO}_{2}$, water vapour and $\mathrm{N}_{2}$ can greatly reduce the explosion characteristics of methane air mixtures [143]. When adequate and standard safety measures such as venting and spacing, flame traps at gas inlets/outlets, and inline $\mathrm{CH}_{4}$ sensors with alarm systems are incorporated into the plant 
design, any significant threat from an explosion hazard can be minimized.

\subsection{Different Means of Partial Aeration in $A D$}

Supply of air directly into the liquid media of the reactor is the commonly used way of oxygen induction, adopted in many studies [28, 49, 53, 59, 100]. A part of the oxygen supplied can however escape into the headspace. This escaped amount of the supplied oxygen can diffuse back into the liquid medium if the aeration is semi-continuous; otherwise a part can be lost with the biogas stream.

Supply of air in headspace in equilibrium with the liquid phase has been used in some studies [25, 27, 47, 74, 106]. This is a suitable way of aeration when only a minute amount of oxygen is intended to be given, especially for research purposes. Use of pure oxygen instead of air is an alternative [47, 105]. According to Guiot et al. [105], air addition did not cause a significant change in the methane production rate in a UASB reactor while pure oxygen addition led to reduced $\mathrm{CH}_{4}$ generation. Pure oxygen could have diffused deeper in the sludge granules and caused inhibition of strict anaerobes, while air aeration could have only had a no or milder inhibition effect due to less oxygen concentration. In air aeration, dilution of biogas by $\mathrm{N}_{2}$ is a disadvantage.

Rathnasiri [30] introduced a novel approach of using a dense polydimethyl siloxane (PDMS) membrane through which oxygen saturated water was circulated to diffuse traces of oxygen into an anaerobic reactor. This technique allows the application of traces of oxygen in a more controlled manner.

We suggest electrolytic aeration as a new concept where an electric current can be used to introduce an aeration effect through water electrolysis. This concept has not yet been tested in any study, but can be a useful method to introduce limited aeration in AD. Electrolytically generated hydrogen, together with oxygen, can also become a substrate for AD. An electrochemical combustion process can also happen concurrently, improving the waste digestion. Another plausible advantage of this method is to very precisely control the level of aeration based on reactor performance data. Feed back control of aeration using a rapid responding control parameter such as hydrogen concentration in biogas stream [144] can be established. This technique must be investigated further to have a greater insight into its applicability. Electrically enhanced hydrolysis is another plausible scenario.

\section{MODELING OF OXYGEN EFFECTS IN $A D$}

Different models have been proposed to describe the complex and interrelated biochemical processes taking place in anaerobic digestion. Among them, the generic model of ADM 1 [23] presented by the IWA mathematical modeling task group has been a subject of great interest during the last decade. There are various other models also describing the anaerobic digestion process to a level of significant accuracy. A good example is the model suggested by Angelidaki et al. [145]. Prediction accuracies of different models is a subject of controversy, naturally, as for all the models. Fuentes et al. [146] reported, for example, that the model by Angelidaki et al. [145] was accurate in predicting the behavior of their mesophilic lab scale fluidized bed reactor. There are also numerous case specific models developed to describe specific reactors with defined type of substrates. Sometimes they may predict those specific cases more accurately than the generic models, like ADM 1.

There was no comprehensive model available to explain the behavior of anaerobic digesters under minute free oxygen load conditions until recent times. Botheju et al. [25] developed a model for this purpose based on ADM 1, to accommodate some of the known oxygen effects in anaerobic digestion. This model, named ADM1-Ox, predicted quite accurately the observed behavior of lab scale anaerobic digesters under different oxygenation conditions and substrates $[25,27,28,46,106]$. ADM1-Ox includes some of the plausible oxygen effects in anaerobic digestion by including seven aerobic uptake processes for the direct hydrolysis products of monosaccharides (simple sugars), amino acids, long chain fatty acids, and the four volatile fatty acids of acetic, propionic, butyric and valeric. The model also consists of modified hydrolysis rate equations to include the acidogenic biomass concentrations, as well as oxygen inhibition factors in the anaerobic processes. All aerobic uptake processes are catalyzed by the facultative acidogenic biomasses. No new biomass type is introduced in the ADM1-Ox, in addition to the seven types of trophic groups originally presented with ADM 1 . This model predicts the existence of an optimum oxygenation point corresponding to a maximum methane yield. Furthermore, it can be used to identify different operating conditions giving rise to positive or negative impacts of oxygenation on biogas/methane generation. This model, in addition to the conventional CSTR arrangement, was also implemented in a biofilm configuration using the Aquasim Biofilm Reactor Compartment [85], following the methodology described previously [147]. ADM 1-Ox was also capable of predicting the oxygen effects observed in an experimental study where the degradation of MEA/waste MEA was investigated [106, 107]. For that purpose, two additional processes of aerobic and anaerobic MEA uptake had to be included in the model [107].

Another model which might have the potential ability to simulate simultaneous aerobic and anaerobic effects is the one proposed by de Gracia et al. [148]. This is a completely new model developed to describe the wastewater sludge (primary and secondary) digestion under aerobic or anaerobic conditions. The basic aim of this model was to facilitate connecting aerobic and anaerobic stages of biological sludge digestion; however, the model is also found to be suitable for simulating the aerobic/anaerobic digestion under oxygen limiting conditions. The model is capable of predicting the formation of VFA when the oxygen supply is limited in aerobic sludge digestion. Inclusion of an energy balance in de Gracia et al.'s [148] model allows the prediction of reactor temperature variation due to aerobic biological heat generation which can be a significant effect in highly aerated conditions. It also includes thermal hydrolysis as a physiochemical transformation process. This allows the model to reproduce digester behavior in autothermal aerobic digestion, which is basically an aerobic sludge digestion process using biochemical heat to elevate the reactor temperature without an external heat source. Generation of VFA in auto-thermal aerobic digestion is well 
documented [101-104]. The applicability of this model for different substrates other than biological sludge has not been tested. It is also not clear whether, or to what extent, this model could be used to analyze the effects of oxygenation on bio-gasification. The process rate equations are not obvious in the publication [148]. It is however observed that two different formulations have been used to describe the hydrolysis under aerobic and anaerobic conditions, separately.

It may also be worthwhile to study the plausibility of using simple mathematical or empirical models (such as the Gompertz equation, e.g. Donoso-Bravo et al. [149]) to predict the oxygen effects in methane generation potential. Such equations can be based on simple mass balance and kinetic analyses. Those kinds of rudimentary formulations are sometimes convenient and cost effective to be used as a "rules of thumb" for basic estimation purposes compared to complicated model simulations requiring more time, effort and expertise.

\section{CONCLUSIONS}

Oxygen can have multifaceted effects in anaerobic biogasification. The overall impact of aeration on the methane yield of a digestion system thus depends on the resultant of these diverse biochemical and physiochemical reactions involving oxygen. The influence of the different reactions eventually depends on the operating conditions of a specific digestion system, such as the nature and concentrations of substrates (soluble, particulate or other specific ingredients like S), hydraulic and operational configuration of the reaction system (CSTR, UASB, batch or continuous) and the characteristics of the inoculum used (biomass concentration, oxygen adaptation, aggregated biomass, etc.).

In spite of the negative impact of oxygen on anaerobic organisms, digesters have a significant capacity to maintain stable performance under a broad range of oxygen input. Anaerobic and aerobic cultures can co-exist in a single reactor environment. Oxygen shielding effect by facultative biomass, diffusion barriers due to aggregated biomass and some intrinsic oxygen tolerance of anaerobic organisms are the main factors contributing to this.

Several experimental studies have been conducted on the oxygen effects in anaerobic digestion. Mechanistic models have been proposed to describe the oxygen effects in $\mathrm{AD}$.

Biogas/methane generation and gas quality can be negatively influenced by aeration, but it can also be affected positively under certain operating conditions.

Oxygen can enhance the hydrolysis and even the acidogenesis stage of AD. Aeration does lead to oxidation of some available substrate by aerobic respiration, removing some of the methane potential. This can be more than compensated for by enhanced hydrolysis in some hydrolysis limited $\mathrm{AD}$ cases. An optimum oxygenation level corresponding to a maximum methane yield exists in such cases.

It is suggested that in phase-separated digestion systems, partial aeration can most suitably be incorporated with the initial hydrolysis stage. This arrangement would facilitate enhanced hydrolysis while minimizing the negative impacts of aeration.
Limited aeration can be a useful strategy to limit VFA accumulation during start-up and transition periods of digesters, avoiding instabilities due to $\mathrm{pH}$ drops and inhibition caused by VFA. This can be used for enhanced starting-up performance in $\mathrm{AD}$ and stable digester operation.

Enhanced effluent quality can be achieved in AD by limited aeration. Partial aeration assisted anaerobic digestion can be an especially useful means of treating a variety of recalcitrant, persistent and eco-toxic organic wastes which are difficult to treat either by aerobic or anaerobic treatment alone. Partial aeration can also help to avoid the formation of toxic $\mathrm{H}_{2} \mathrm{~S}$ in the digestion of $\mathrm{S}$ rich substrates, leading to better effluent water and biogas quality.

Some, but not dramatic, changes in the microbial community structure can be expected due to limited aeration in $\mathrm{AD}$.

It is suggested that partial aeration assisted anaerobic digestion can become a useful waste treatment and a renewable energy generation scheme with multiple benefits. Further research on the topic, especially related to full scale applications, must be performed in order to establish this as a standard treatment option.

\section{ACKNOWLEDGEMENTS}

The research project under which this work has been carried out is funded principally by grants from the Research Council of Norway. A part of the funding is also contributed through Telemark Technological Research \& Development center (Tel.Tek). Authors acknowledge the support given by the staff members of Telemark University College. A special thank to the library staff who rendered a prompt service in finding some of the literature used here. Chief Laboratory Engineer Hildegunn H. Haugen also helped us on many occasions.

\section{REFERENCES}

[1] D. Deublein and A. Steinhauser, Biogas from waste and renewable resources; An introduction. Weinheim: Wiley-VCH Verlag $\mathrm{GmbH}$ \& Co. KGaA, 2008.

[2] P. J. He, "Anaerobic digestion: An intriguing long history in China", Waste Management, vol. 30, pp. 549-550, 2010.

[3] S. Verma, "Anaerobic digestion of biodegradable organics in municipal solid wastes", MSc. thesis, Columbia University, 2002.

[4] F. Monnet, "An introduction to anaerobic digestion of organic wastes", Final Report by Remade Scotland Initiative, 2003. Available online: visited on 17.05.2010. http://www.biogasmax.eu/ media/introanaerobicdigestion_073323000_1011_24042007.pdf

[5] Y. Chen, J. J. Cheng, and K. S. Creamer, "Inhibition of anaerobic digestion process: A review", Bioresource Technology, vol. 99, pp. 4044-4064, 2008.

[6] A. Ward, P. J. Hobbs, P. J. Holliman, and D. L. Jones, "Optimisation of the anaerobic digestion of agricultural resources", Bioresource Technology, vol. 99, pp. 7928-7940, 2008.

[7] F. Blumensaat and J. Keller, "Modeling of two-stage anaerobic digestion using the IWA Anaerobic Digestion Model no. 1 (ADM 1)", Water Research, vol. 39, pp. 171-183, 2005.

[8] M. Murto, L. Bjornsson, and B. Mattiasson, "Impact of food industrial waste on anaerobic co-digestion of sewage sludge and pig manure", Journal of Environmental Management, vol. 70, pp. 101-107, 2004.

[9] G. Tchobanoglous, F. L. Burton, and H. D. Stensel, Meltcalf \& Eddy, Inc.'s Wastewater Engineering: Treatment, Disposal, and Reuse. Tata McGraw-Hill publishing company Ltd, $4^{\text {th }}$ Edition, 2003.

[10] K. Braber, "Anaerobic digestion of municipal solid waste; A modern waste disposal option on the verge of breakthrough", Biomass and Bioenergy, vol. 9 (1 - 5), pp. 365-376, 1995. 
[11] K. Salomon and E. E. S. Lora, "Estimate of the electric energy generating potential for different sources of biogas in Brazil", Biomass and Bioenergy, vol. 33, pp. 1101-1107, 2009.

[12] L. Yu, K. Yaoqiu, H. Ningsheng, W. Zhifeng, and X. Lianzhong, "Popularizing household-scale biogas digesters for rural sustainable energy development and greenhouse gas mitigation", Renewable Energy, vol. 33, pp. 2027-2035, 2008.

[13] M. Lantz, M. Svensson, L. Björnsson, and P. Börjesson, "The prospects for an expansion of biogas systems in Sweden Incentives, barriers and potentials", Energy Policy, vol. 35, pp. 1830-1843, 2007.

[14] I. M. Buendía, F. J. Fernández, J. Villaseñor, and L. Rodríguez, "Feasibility of anaerobic co-digestion as a treatment option of meat industry wastes", Bioresource Technology, vol. 100, pp. 19031909, 2009.

[15] M. J. Cuetos, X. Gómez, M. Otero, and A. Moran, "Anaerobic digestion of solid slaughterhouse waste (SHW) at laboratory scale: Influence of co-digestion with the organic fraction of municipal solid waste (OFMSW)", Biochemical Engineering Journal, vol. 40, pp. 99-106, 2008.

[16] H. B. Nielsen, H. Uellendahl, and B. K. Ahring, "Regulation and optimization of the biogas process: Propionate as a key parameter", Biomass and Bioenergy, vol. 31, pp. 820-830, 2007.

[17] M. Berglund, and P. Börjesson, "Assessment of energy performance in the life-cycle of biogas production", Biomass and Bioenergy, vol. 30, pp. 254-266, 2006.

[18] J. B. H. Nielsen, T. A. Seadi, and P. O. Popiel, "The future of anaerobic digestion and biogas utilization", Bioresource Technology, vol. 100, pp. 5478-5484, 2009.

[19] D. Botheju, Ø. Svalheim, B. Rydtun, J. Johansen, T. K. Haraldsen, and R. Bakke, "Fertilizer production by digestate nitrification", in proceedings of the $12^{\text {th }}$ European Biosolids and Organic Resources Conference, Manchester, UK, November 2007.

[20] M. Simon, "A new approach to produce soil conditioner and biogas from organic waste", A környezetkímélö, gazdaságos napraforgótermesztés feltételrendszere az EU-ban. Agrofórum, November 2003.

[21] L. Krause, N. N. Diaz, R. A. Edwardse, K-H. Gartemann, H. Krömeke, H. Neuweger, A. Pühler, K. J. Runte, A. Schlüter, J. Stoye, R. Szczepanowski, A. Tauch, and A. Goesmann, "Taxonomic composition and gene content of a methane-producing microbial community isolated from a biogas reactor", Journal of Biotechnology, vol. 136, pp. 91-101, 2008.

[22] H. N. Gavala, U. Yenal, I. V. Skiadas, P. Westermann, and B. K. Ahring, "Mesophilic and thermophilic anaerobic digestion of primary and secondary sludge: Effect of pre-treatment at elevated temperature", Water Research, vol. 37, pp. 4561-4572, 2003.

[23] D. J. Batstone, J. Keller, I. Angelidaki, S. Kalyuzhnyi, S. G. Pavlostathis, A. Rozzi, W. Sanders, H. Siegrist, and V. Vavilin, Anaerobic Digestion Model no. 1. IWA task group on modeling of anaerobic digestion processes, London: IWA publishing, 2002.

[24] G. Lyberatos and I. V. Skiadas, "Modeling of anaerobic digestion a review", Global Nest: The International Journal, vol. 1 (2), pp. 63-76, 1999.

[25] D. Botheju, B. Lie, and R. Bakke, "Oxygen Effects in Anaerobic Digestion", Modelling, Identification and Control, vol. 30, no 4, pp. 191-201, 2009a.

[26] P. Kaparaju, L. Ellegaard, and I. Angelidaki, "Optimisation of biogas production from manure through serial digestion: Lab-scale and pilot-scale studies", Bioresource Technology, vol. 100, pp. 701-709, 2009.

[27] D. Botheju, G. Samarakoon, C. Chen, and R. Bakke, "An experimental study on the effects of oxygen in bio-gasification; Part 1", in proceedings of the International Conference on Renewable Energies and Power Quality (ICREPQ 10), Granada, Spain, March, 2010. Archived in Renewable Energies \&Power Quality Journal (RE\&PQJ), vol. 8, 2010d.

[28] D. Botheju, G. Samarakoon, C. Chen, and R. Bakke, "An experimental study on the effects of oxygen in bio-gasification; Part 2", in proceedings of the International Conference on Renewable Energies and Power Quality (ICREPQ 10), Granada, Spain, March, 2010. Archived in Renewable Energies \&Power Quality Journal (RE\&PQJ), vol. 8, 2010e.

[29] M. F. Polanco, I. Diaz, S. I. Pérez, A. C. Lopes, and F. F. Polanco, "Hydrogen sulphide removal in the anaerobic digestion of sludge by micro-aerobic processes: Pilot plant experience", Water Science and Technology, vol. 60, no. 12, pp. 3045-3050, 2009a

[30] P. G. Rathnasiri, "Anaerobic digestion process using membrane integrated micro-aeration", PhD Thesis, Norwegian University of Science and Technology (NTNU), 2009.

[31] L. Appels, J. Baeyens, J. Degreve, and R. Dewil, "Principles and potential of the anaerobic digestion of waste-activated sludge", Progress in Energy and Combustion Science, vol. 34, pp. 755-781, 2000.

[32] M. Myint, N. Nirmalakhandan, and R. E. Speece, "Anaerobic fermentation of cattle manure: Modeling of hydrolysis and acidogenesis", Water Research, vol. 41, pp. 323-332, 2007.

[33] A. Schluter, T. Bekel, N. N. Diaz, M. Dondrup, R. Eichenlaub, KH. Gartemann, I. Krahn, L. Krause, H. Kromeke, O. Kruse, J. H. Mussgnug, H. Neuweger, K. Niehaus, A. Puhler, K. J. Runte, R. Szczepanowski, A. Tauch, A. Tilker, P. Viehover, and A. Goesmann, "The metagenome of a biogas-producing microbial community of a production-scale biogas plant fermenter analysed by the 454-pyrosequencing technology", Journal of Biotechnology, vol. 136, pp. 77-90, 2008.

[34] S. Hasegawa, N. Shiota, K. Katsura, and A. Akashi, "Solubilization of organic sludge by thermophilic aerobic bacteria as a pretreatment for anaerobic digestion", Water Science and Technology, vol. 41, no. 3, 163-169, 2000.

[35] G. D. Gioannis, L. F. Diaz, A. Muntoni, and A. Pisanu, "Twophase anaerobic digestion within a solid waste/wastewater integrated management system", Waste Management, vol. 28, pp. 1801-1808, 2008.

[36] H. Yang, P. Shao, T. Lu, J. Shen, W. Dufu, Z. Xu, and X. Yuan, "Continuous bio-hydrogen production from citric acid wastewater via facultative anaerobic bacteria", International Journal of Hydrogen Energy, vol. 31, pp. 1306-1313, 2006.

[37] C. P. D'Souza, R. H. Balasubramanya, "Microbial ecology of solid cellulosic materials during aerobic digestion and anaerobic fermentation", Bioresource Technology, vol. 69, pp. 285-287, 1999.

[38] S-Y. Lun, J. Wu, and J. Chen, "Anaerobic waste treatment: Efficient separation of the acid and methane forming phases using two UASB reactors", Process Biochemistry, vol. 30, no. 6, pp. 523$529,1995$.

[39] S. Fukuzaki, N. Nishio, and S. Nagai, "Kinetics of the methanogenic fermentation of acetate", Applied and Environmental Microbiology, vol. 56 (10), pp. 3158-3163, 1990.

[40] W. B. Whitman, T. L. Bowen, and D. R. Boone, "The methanogenic bacteria", in Prokaryotes, vol. 3; A handbook on the biology of bacteria, D. M., S. Falkow, E. Rosenberg, K-H. Schleifer, and E. Stackebrandt, Eds. $3^{\text {rd }}$ ed., pp. 165-207, 2006.

[41] M. Oslaj, B. Mursec, and P. Vindis, "Biogas production from maize hybrids", Biomass and Bioenergy, vol. 34, no. 11, pp. 1538$1545,2010$.

[42] S. Rasi, A. Veijanen, and J. Rintala, "Trace compounds of biogas from different biogas production plants", Energy, vol. 32, pp. 13751380, 2007.

[43] S. S. Kapdi, V. K. Vijay, S. K. Rajesh, and R. Prasad, "Biogas scrubbing, compression and storage: perspective and prospectus in Indian context", Renewable Energy, vol. 30, pp. 1195-1202, 2005.

[44] M. T. Kato, J. A. Field, and G. Lettinga, "Anaerobic tolerance to oxygen and the potentials of anaerobic and aerobic cocultures for wastewater treatment", Brazilian Journal of Chemical Engineering, vol. 14, no. 4, 1997.

[45] G. Liden, C. J. Franzen, and C. Nicklasson, "A new method for studying microaerobic fermentation. (I): A theoretical analysis of oxygen programmed fermentation", Biotechnology and Bioengineering, vol. 44, pp. 419-427, 1994.

[46] D. Botheju, B. Lie, and R. Bakke, "Oxygen effects in Anaerobic Digestion - II", Modeling, Identification and Control, vol. 31, no. 2, pp. 55-65, $2010 \mathrm{f}$.

[47] D. Botheju, and R. Bakke, "Bio-gasification under partially aerated conditions; Results from batch experiments", Submitted Manuscript to the proceedings of the Linnaeus Eco-Tech'10, The $7^{\text {th }}$ International Conference on the Establishment of Cooperation Between Companies and Institutions in the Nordic Countries, the Baltic Sea Region, and the World, Kalmar, Sweden, November 2010.

[48] M. F. Polanco, I. Diaz, S. I. Pérez, and F. F. Polanco, "Free $\mathrm{H}_{2} \mathrm{~S}$ biogas: From anaerobic to microaerobic", in proceedings of the 
International Conference on Strategy for Anaerobic Biotechnology, Xian, China, November, 2009, pp. 151-159, 2009b.

[49] J. E. Johansen, and R. Bakke, "Enhancing hydrolysis with microaeration", Water Science and Technology, vol. 53, no. 8, pp. 43-50, 2006.

[50] S. J. Pirt, and Y. K. Lee, "Enhancement of methanogenesis by traces of oxygen in bacterial digestion of biomass", FEMS Microiology Letters, vol. 18, pp. 61-63, 1983.

[51] L-B. Chu, X-W. Zhang, X. Li, and F-L. Yang, "Simultanious removal of organic substances and nitrogen using a membrane bioreactor seeded with anaerobic granular sludge under oxygenlimited conditions", Desalination, vol. 172, pp. 271-280, 2005.

[52] D. H. Zitomer, and J. D. Shrout, "Feasibility and benefits of methanogenesis under oxygen-limited condition", Waste Management, vol. 18, pp. 107-116, 1998.

[53] D. H. Zitomer, "Stoichiometry of combined aerobic and methanogenic COD transformation", Water Research, vol. 32, no. 3, pp. 669-676, 1998.

[54] C. F. Shen, and S. R. Guiot, "Long term impact of dissolved $\mathrm{O}_{2}$ on the activity of anaerobic granules", Biotechnology and Bioengineering, vol. 49, pp. 611-620, 1996.

[55] M. T. Kato, J. A. Field, and G. Lettinga, "High tolerance of methanogens in granular sludge to oxygen", Biotechnology and Bioengineering, vol. 42, pp. 1360-1366, 1993.

[56] Y. Song, and B. E. Logan, "Effect of $\mathrm{O}_{2}$ exposure on perchlorate reduction by Dechlorosoma sp. KJ", Water Research, vol. 38, pp. 1626-1632, 2004.

[57] A. Ueki, K. One, A. Tsuchiya, and K. Ueki, "Survival of methanogens in air-dried paddy field soil and their heat tolerance", Water Science and Technology, vol. 36, no. (6-7), pp. 517-522, 1997.

[58] K. F. Jarrell, "Extreme oxygen sensitivity in methanogenic archaebacteria", Bioscience, vol. 35, no. 5, pp. 298-302, 1985.

[59] L. Hao, P. J. He, F. Lu, L. Shao, and M. Zhu, "Regulating the hydrolysis of organic waste by micro-aeration and effluent recirculation", Waste Management, vol. 29, pp. 2042-2050, 2009.

[60] P. S. Jagadabhi, P. Kaparaju, and J. Rintala, "Effect of microaeration and leachate replacement on COD solubilization and VFA production during mono-digestion of grass-silage in one-stage leach-bed reactors", Bioresource Technology, vol. 101, pp. 28182824, 2009.

[61] M. Climent, I. Ferrer, M. d. M. Baeza, A. Artola, F. V'azquez, and $\mathrm{X}$. Font, "Effects of thermal and mechanical pretreatments of secondary sludge on biogas production under thermophilic conditions", Chemical Engineering Journal, vol. 133, pp. 335-342, 2007.

[62] R. Ferrara, R. Barberis, R. Jodice, and E. Vicenzino, "Influence of kinetics of hydrolysis, acidogenesis and methanogenesis on enhancement of the production of biogas from animal excreta", Agricultural Wastes, vol. 11, pp. 79-90, 1984.

[63] M. Henze, W. Gujer, T. Mino, T. Matsuo, M. C. Wentzel, and G. V. R. Marais, Activated sludge model no. 2; IAWQ Scientific and Technical Report no. 3, London: IAWQ, 1995.

[64] M. Nordkvist, N. B. S. Jensen, and J. Villadsen, "Glucose metabolism in Lactococcus Lactis MG1363 under different aeration conditions: Requirement of acetate to sustain growth under microaerobic conditions", Applied and Environmental Microbiology, vol. 69, no. 6, pp. 3462-3468, 2003.

[65] C. Chen, N. Ren, A. Wang, L. Liu, and D-J. Lee, "Enhanced performance of denitrifying sulfide removal process under microaerobic condition", Journal of Hazardous Materials, vol. 179, pp. 1147-1151, 2010.

[66] R. A. Ludwig, "Microaerophilic bacteria transduce energy via oxidative metabolic gearing - Mini review", Research in Microbiology, vol. 155, pp. 61-70, 2004.

[67] C. J. Franzen, E. Albers, and C. Niklasson, "Use of the inlet gas composition to control the respiratory quotient in microaerobic bioprocesses", Chemical Engineering Science, vol. 51, no, 13, pp. 3391-3402, 1996.

[68] A-P. Zeng, and W-D. Deckwer, "Bioreactor techniques under microaerobic conditions; from molecular level to pilot plant reactors", Chemical Engineering Science, vol. 51, no, 10, pp. 23052314, 1996.

[69] M. E. Barley, A. Bekker, and B. Krapez, "Late Archean to Early Paleoproterozoic global tectonics, environmental change and the rise of atmospheric oxygen", Earth and Planetary Science Letters, vol. 238, pp. 156-171, 2005.

[70] G. Gottschalk, and S. Peinemann, The anaerobic life: A handbook on the biology of bacteria, vol. 1: ecophysiology, isolation, identification, application. New York: Springer-Verlag, $2^{\text {nd }}$ ed, 1992, pp. 300-311.

[71] R. D. Rolfe, D. J. Hentges, B. J. Campbell, and J. T. Barrett, "Factors related to the oxygen tolerance of anaerobic bacteria", Applied and Environmental Microbiology, vol. 36, no 2, pp. 306313, 1978.

[72] A. Kiener, and T. Leisinger, "Oxygen sensitivity of methanogenic bacteria", Systematic and Applied Microbiology, vol. 4, no.3, pp. 305-312, 1983.

[73] R. E. Hungate, and J. Macy, "The roll-tube method for cultivation of strict anaerobes", Bulletins from the Ecological Research Committee, vol. 17, pp. 123-126, 1973.

[74] J. Gerritse, F. Schut, and J. C. Gottschal, "Mixed chemostat cultures of obligately aerobic and fermentative or methanogenic bacteria grown under oxygen-limiting conditions", FEMS Microiology Letters, vol. 66, pp. 87-94, 1990.

[75] R. I. Scott, T. N. Williams, and D. Lloyd, "Oxygen sensitivity of methanogenesis in rumen and anaerobic digester populations using mass spectrometry", Biotechnology Letters, vol. 5, no. 6, 375-380, 1983

[76] R. E. Hungate, "A roll tube method for cultivation of strict anaerobes", Methods in Microbiology, vol. 3B, pp. 117-132, 1969.

[77] J. H. Martin, and D. C. Savage, "Degradation of DNA in cells and extracts of the obligate anaerobic bacterium Roseburia cecicola upon exposure to air", Applied and Environmental Microbiology, vol. 54, no. 6, pp. 1619-1621, 1988.

[78] P. G. Rathnasiri, D. Botheju, and R. Bakke, "Effects of biofilm formation on oxygen transfer membranes in Membrane Microaerated Anaerobic Digesters", in proceedings of the Final MBRNetwork Workshop, Berlin, Germany, March/April, 2009.

[79] D. Botheju, P. G. Rathnasiri, and R. Bakke, "Biofilms on oxygen transfer membranes in membrane micro-aerated anaerobic digesters", in proceedings of the IWA Biofilm Technologies Conference, Singapore, January 2008.

[80] W. Zhou, T. Imai, M. Ukita, F. Li, and A. Yuasa, "Effect of limited aeration on the anaerobic treatment of evaporator condensate from a sulfite pulp mill”, Chemosphere, vol. 66, pp. 924-929, 2007.

[81] A. Conklin, R. Bucher, H. D. Stensel, and J. Ferguson, "Effects of oxygen exposure on anaerobic digeter sludge", Water Environment Research, vol. 79, no. 4, pp. 396-405, 2007.

[82] B. A. Huser, K. Wuhrmann, and A. J. B. Zehnder, "A new acetotrophic non hydrogen oxidation methane bacterium", Archives of Microbiology, vol. 132, pp. 1-9, 1982.

[83] V. Peter, and R. Conrad, "Methanogenic and other strictly anaerobic bacteria in desert soils and other oxic soils", Applied Environmental Microbiology, vol. 61, pp. 1673-1676, 1995.

[84] J. Gerritse, and J. C. Gottschal, "Two-membered mixed cultures of methanogenic and aerobic bacteria in $\mathrm{O}_{2}$ limited chemostats", Journal of General Microbiology, vol. 139, pp. 1853-1860, 1993.

[85] D. Botheju, B. Lie, and R. Bakke, "Simulation of a biofilm process by the ADM 1 -Ox model", Submitted Manuscript to the proceedings of the $51^{\text {st }}$ SIMS Conference on Simulation and Modeling, SIMS 2010, Oulu, Finland, October, 2010g.

[86] F. P. V. Zee, S. Villaverde, P. A. Garcia, and F. F. Polanco, "Sulfide removal by moderate oxygenation of anaerobic sludge environments", Bioresource Technology, vol. 98, pp. 518-524, 2007.

[87] A. Brune, "Termite guts: the world's smallest bioreactors", Trends in Biotechnology, vol. 16, no. 1, pp. 16-21, 1998.

[88] A. E. Ghaly, and A. A. El-Taweel, "Effects of micro-aeration on the growth of Candida pseudotropicalis and production of ethanol during batch fermentation of cheese whey", Bioresource Technology, vol. 52, pp. 203-217, 1995.

[89] M. S. A. Tango, and A. E. Ghaly, "Amelioration of lactic acid production from cheese whey using micro-aeration", Biomass and Bioenergy, vol. 17, pp. 221-238, 1999.

[90] X. Chen, Z. L. Xiu, J. F. Wang, D. J. Zhang, and P. Xu, "Stoichiometric analysis and experimental investigation of glycerol bioconversion to 1,3-propanediol by Klebsiella pneumoniae under microaerobic conditions", Enzyme Microb. Technol. vol. 33 pp. 386-394, 2003. 
[91] A. Mshandete, L. Börjesson, A. K. Kivaisi, S. T. Rubindamayugi, and B. Mattiasson, "Enhancement of anaerobic batch digestion of sisal pulp waste by mesophilic aerobic pre-treatment", Water Research, vol. 39, pp. 1569-1575, 2005.

[92] D. M. O'Keefe, and D. P. Chynoweth, "Influence of phase separation, leachate recycle and aeration on treatment of municipal solid waste in simulated landfll cells", Bioresource Technology, vol. 72, pp. 55-66, 2000.

[93] A. Joss, W. Edelmann, H. R. Siegrist, and F. Widmer, "Microaerobic biowaste treatment", in proceedings of the $2^{\text {nd }}$ International Symposium on Anaerobic Digestion of Solid Wastes, Barcelona, Spain, June, 1999.

[94] W. Charles, L. Walker, and R. Cord-Ruwisch, "Effect of preaeration and inoculum on the start-up of batch thermophilic anaerobic digestion of municipal solid waste", Bioresource Technology, vol. 100, pp. 2329-2335, 2009.

[95] P. H. L. Nguyen, P. Kuruparan, and C. Visvanathan, "Anaerobic digestion of municipal solid waste as a treatment prior to landfill", Bioresource Technology, vol. 98, no. 2, pp. 380-387, 2007.

[96] R. Goel, T. Matsuo, T. Mino, and H. Satoh, "Enzyme activities under anaerobic and aerobic condition in activated sludge sequencing batch reactor", Water Research, vol. 32, no. 7, pp. 2081-2088, 1997.

[97] R. Dewil, L. Appels, J. Baeyens, and J. Degreve, "Peroxidation enhances the biogas production in the anaerobic digestion of biosolids", Journal of Hazardous Material, vol. 146, pp. 577-581, 2007.

[98] T. Duangmanee, S. K. Khanal, and S. Sung, "Micro-aeration for sulfide removal in anaerobic treatment of high-solid wastewater: A pilot scale study", in AgSTAR National Conference Sacramento, California, November, 2007.

[99] S. Azabou, T. Mechichi, and S. Sayadi, "Sulfate reduction from phosphogypsum using a mixed culture of sulfate-reducing bacteria", Int. Biodeterioration \& Biodegradation, vol. 56, pp. 236242, 2005

[100] Y. Tang, T. Shigematsu, Ikbal, S. Morimura, and K. Kida, "The effects of micro-aeration on the phylogenetic diversity of microorganisms in a thermophilic anaerobic municipal solid waste digester", Water Research, vol. 38, pp. 2537-2550, 2004.

[101] A. Chu, D. S. Mavinic, H. G. Kelly, and W. D. Ramey, "Volatile fatty acid production in thermophilic aerobic digestion of sludge", Water Research, vol. 28, no. 7, pp. 1513-1522, 1994.

[102] S. Borowski and J. S. Szopa, "Experiences with the dual digestion of municipal sewage sludge", Bioresource Technology, vol. 98, pp. 1199-1207, 2007.

[103] J. O. Ugwuanyi, L. M. Harvey, and B. McNeil, "Effect of digestion temperature and $\mathrm{pH}$ on treatment efficiency and evolution of volatile fatty acids during thermophilic aerobic digestion of model high strength agricultural waste", Bioresource Technology, vol. 96, pp. 707-719, 2005.

[104] A. Chu, D. S. Mavinic, W. D. Ramey and, H. G. Kelly, “A biochemical model describing volatile fatty acid nmetabolism in thermophilic aerobic digestion of wastewater sludge", Water Research, vol. 30, no. 8, pp. 1759-1770, 1996.

[105] S. R. Guiot, A. Patoine, and R. J. Stephenson, "Effects of oxygenation and upflow liquid velocity on a coupled anaerobic/aerobic reactor system", Water Research, vol. 33, no. 12, pp. 2855-2863, 1999.

[106] D. Botheju, Y. Li, J. Hovland, T. Risbergb, H. A. Haugen, C. Dinamarca, and R. Bakke, "Biogasification of waste monoethanolamine generated in post combustion $\mathrm{CO}_{2}$ capture", in proceedings of the $2^{\text {nd }}$ Annual Gas Processing Symposium, Doha, Qatar, January, 2010. Published in Advances in Gas Processing, vol. 2 (Book series), Elsevier, $2010 \mathrm{~b}$.

[107] D. Botheju, J. Hovland, H. A. Haugen, and R. Bakke, "Monoethanolamine biodegradation processes", in proceedings of the $2^{\text {nd }}$ Annual Gas Processing Symposium, Doha, Qatar, January, 2010. Published in the Advances in Gas Processing, vol. 2 (Book series), Elsevier, 2010c.

[108] D. Botheju, Y. Li, J. Hovland, T. Risbergb, H. A. Haugen, C. Dinamarca, and R. Bakke, "Oxygenated anaerobic treatment of amine wastes generated in post combustion $\mathrm{CO}_{2}$ capture", in $5^{\text {th }}$ Trondheim Conference on $\mathrm{CO}_{2}$ Capture, Transport and Storage, Trondheim, Norway, June 2009b.
[109] Y. Chen, X. Feng, and F. Ye, "Advance start-up of anaerobic attached film expanded bed reactor by pre-aeration of biofilm carrier", Bioresource Technology, vol. 96, pp. 115-119, 2005.

[110] W. G. Characklis and K. C. Marshall, Biofilms. New York : John Wiley publishers, 1990.

[111] C. Dumas, S. Perez, E. Paul, and X. Lefebvre, "Combined thermophilic aerobic process and conventional anaerobic digestion: Effect on sludge biodegradation and methane production", Bioresource Technology, vol. 101, pp. 2629-2636, 2010.

[112] R. T. Romano, R. Zhang, S. Teter, and J. A. McGarvey, "The effect of enzyme addition on anaerobic digestion of Jose' tall wheatgrass", Bioresource Technology, vol. 100, pp. 4564-4571, 2009.

[113] M. R. Salsabil, A. Prorot, M. Casellasa, and C. Dagot, "Pretreatment of activated sludge: Effect of sonication on aerobic and anaerobic digestibility", Chemical Engineering Journal, vol. 148, pp. 327-335, 2009.

[114] I. Ferrer, S. Ponsá, F. Vázquez, and X. Font, "Increasing biogas production by thermal $\left(70^{\circ} \mathrm{C}\right)$ sludge pre-treatment prior to thermophilic anaerobic digestion", Biochemical Engineering Journal, vol. 42, pp. 186-192, 2008.

[115] A. B. Martinez, H. Carrére, D. Patureau, and J. Delgenés, "Ozone pre-treatment as improver of PAH removal during anaerobic digestion of urban sludge", Chemosphere, vol. 68, pp. 1013-1019, 2007.

[116] K. Ohtaguchi, K. Koide, and T. Yokoyama, "An ecotechnologyintegerated MEA process for $\mathrm{CO}_{2}$ removal", Energy Conversion Management, vol. 36, no. 6-9, pp. 401-404, 1995.

[117] S. Sandhya, S. Padmavathy, K. Swaminathan, Y. V. Subrahmanyam, and S. N. Kaul, "Microaerophilic - aerobic sequential batch reactor for treatment of azo dyes containing simulated wastewater", Process Biochemistry, vol. 40, pp. 885-890, 2005.

[118] J-S. Chang, C. Chou, Y-C. Lin, P-J. Lin, J-Y. Ho, and T. L. Hu, "Kinetic characteristics of bacterial azo-dye decolorization by Pseudomonaz Luteola", Water Research, vol. 35, no. 12, pp. 28412850, 2001.

[119] J. S. Knapp and P. S. Newby, "The microbiological decolorization of an industrial effeluent containing a diazo-linked chromophore", Water Research, vol. 29, no. 7, pp. 1807-1809, 1995.

[120] D. de. Beer, P. Stoodley, F. Roe, and Z. Lewandowski, "Effects of biofilm structures on oxygen distribution and mass transport", Biotechnology and Bioengineering, vol. 43, pp. 1131-1138, 1994.

[121] R. W. Robinson, D. E. Akin, R. A. Nordstedt, M. V. Thomas, and H. C. Aldrich, "Light and electron microscopic examination of methane producing biofilms from anaerobic fixed bed reactors", Applied and Environmental Microbiology, vol. 48, no. 1, pp. 127136, 1984.

[122] W. Wu, J. Hu, X. Gu, Y. Zhao, H. Zhang, and G. Gu, "Cultivation of anaerobic granular sludge in UASB reactors with aerobic activated sludge as seed", Water Research, vol. 21, no. 7, pp. 789799, 1987.

[123] P. Bhunia, and M. M. Ghangrekar, "Required minimum granule size in UASB reactor and characteristics variation with size", Bioresource Technology, vol. 98, pp. 994-999, 2007.

[124] J. P. Juanga, P. Kuruparan, and C. Visvanathan, "Optimizing combined anaerobic digestion process of organic fraction of municipal solid waste", in International Conference on Integrated Solid Waste Management in Southeast Asian Cities, Siem Reap, Cambodia, July, 2005.

[125] A. Akashi, S. Hasegawa, K. Katsura, and N. Shiota, "Solubalization of organic sludge by thermophilic aerobic bacteria as a pretreatment for anaerobic digestion", Water science and technology, vol. 41, no. 3, pp. 163-169, 2000.

[126] Y. J. Chan, M. F. Chong, C. L. Law, and D. G. Hassell, "A review on anaerobic - aerobic treatment of industrial and municipal wastewater", Chemical Engineering Journal, vol. 155, pp. 1-18, 2009.

[127] Y. Wei, R. T. V. Houten, A. R. Borger, and D. H. Eikelboom, "Minimization of excess sludge production for biological wastewater treatment", Water Research, vol. 37, pp. 4453-4467, 2003.

[128] D. Botheju, Ø. Svalheim, and R. Bakke, "Digestate nitrification for nutrient recovery", Open Waste Management Journal, vol. 3, pp. 1$12,2010 \mathrm{a}$. 
[129] S. R. Smith, N. L. Lang, K. H. M. Cheung, and K. Spanoudaki, "Factors controlling pathogen destruction during anaerobic digestion of biowastes", Waste Management, vol. 25, pp. 417-425, 2005.

[130] V. Parravicini, K. Svardal, R. Hornek, and H. Kroiss, "Aeration of anaerobically digested sewage sludge for COD and nitrogen removal: Optimization at large scale", Water Science and Technology, vol. 57, no. 2, pp. 257-264, 2008.

[131] G. D. Zupancic and M. Ros, "Aerobic and two stage anaerobic aerobic sludge digestion with pure oxygen and air aeration", Bioresource Technology, vol. 99, pp. 100-109, 2008.

[132] T. B. E. Hadj, S. Astals, A. Gali, S. Mace, and J. Mata-Alvarez, "Ammonia influence in anaerobic digestion of OFMSW", Water Science and Technology, vol. 59, no. 6, pp. 1153-1158, 2009.

[133] N. Bernet, N. Delgenes, J. C. Akunna, J. P. Delgenes, and R. Moletta, "Combined anaerobic aerobic SBR for the treatment of piggery wastewater", Water Research, vol. 34, no. 2, pp. 611-619, 2000.

[134] L. T. Henry, and C. D. J. Raper, "Effects of root-zone acidity on utilization of nitrate and ammonium in tobacco plants", Journal of Plant Nutrition, vol. 12, no. 7, pp. 811-826, 1989.

[135] M. Lægreid, O. C. Bøckman, and O. Kaarstad, Agriculture fertilizers and the environment. Norway: CABI publishing in association with Norsk Hydro ASA, 1999.

[136] E. Lie, and T. Welander, "Influence of dissolved oxygen and oxidation reduction potential on the denitrification rate of activated sludge”, Water Science and Technology, vol. 30, no. 6, pp. 91-100, 1994.

[137] M. Kim, Y. H. Ahn, and R. E. Speece, "Comparative process stability and efficiency of anaerobic digestion; mesophilic vs thermophilic", Water Research, vol. 36, pp. 4369-4385, 2002.

[138] R. Borja, A. Martin, C. J. Banks, V. Alonso, and A. Chica, "A kinetic study of anaerobic digestion of olive mill wastewater at mesophilic and thermophilic temperatures", Environmental Pollution, vol. 88, pp. 13-18, 1995.

[139] A. O. Wagner, C. Malin, G. Gstraunthaler, and P. Illmer, "Survival of selected pathogens in diluted sludge of a thermophilic waste treatment plant and in NaCl-solution under aerobic and anaerobic conditions", Waste Management, vol. 29, pp. 425-429, 2009.
[140] Y-C. Song, S-J. Kwon, and J-H. Woo, "Mesophilic and thermophilic temperature co-phase anaerobic digestion compared with single stage mesophilic and thermophilic digestion of sewage sludge", Water Research, vol. 38, pp. 1653-1662, 2004.

[141] D. A. J. Wase and C. F. Forster, "Biogas - fact or fantasy", Biomass, vol. 4, pp. 127-142, 1984.

[142] The Engineering toolbox: Tools and basic information for design, engineering and construction of technical applications. Available online: http://www.engineeringtoolbox.com/

[143] L. Dupont, and A. Accorsi, "Explosion characteristics of synthesised biogas at various temperatures", Journal of Hazardous Materials, vol. B136, pp. 520-525, 2006.

[144] J. Rodriguez, G. Ruiz, F. Molina, E. Roca, and J. M. Lame, “A hydrogen-based variable-gain controller for anaerobic digestion processes", Water Science and Technology, vol. 54, no. 2, pp. 5762, 2006.

[145] I. Angelidaki, L. Ellegaard, and B. K. Ahring, "A comprehensive model of anaerobic bioconversion of complex substrates to biogas", Biotechnology and Bioengineering, vol. 63, no. 5, pp. 363372, 1999.

[146] M. Fuentes, N. J. Scenna, P. A. Aguirre, and M. C. Mussati, "Application of two anaerobic digestion models to biofilm systems", Biochemical Engineering Journal, vol. 38, pp. 259-269, 2008.

[147] D. Botheju, and R. Bakke, "Implementation of ADM 1 in AQUASIM Biofilm Reactor Compartment", in proceedings of the $49^{\text {th }}$ SIMS Conference on Simulation and Modeling, SIMS 2008, Oslo, Norway, October, 2008.

[148] M. de-Gracia, P. Grau, E. Huete, J. Gomez, J. L. Garcia-Heras, and E. Ayesa, "New generic mathematical model for WWTP sludge digesters operating under aerobic and anaerobic conditions: Model building and experimental verification”, Water Research, vol. 43, pp. 4626-4642, 2009.

[149] A. Donoso-Bravo, S. I. Pérez-Elvira, and F. Fdz-Polanco, "Application of simplified models for anaerobic biodegradability tests: Evaluation of pre-treatment processes", Chemical Engineering Journal, vol. 160, pp. 607-614, 2010. 